\title{
Seismic Toughness and Failure Mechanisms of Reduced Web- Section Beams: Phase 2 Tests
}

\author{
MYOUNGSU SHIN ${ }^{1}$, SEUNG-PIL KIM ${ }^{1}$, ARNE HALTERMAN ${ }^{2}$, and MARK ASCHHEIM ${ }^{3 *}$
}

\author{
${ }^{1}$ School of Urban and Environmental Engineering, Ulsan National Institute of Science and \\ Technology, Ulsan, Korea \\ ${ }^{2}$ Holmes Culley, San Francisco, California, USA \\ ${ }^{3}$ Department of Civil Engineering, Santa Clara University, Santa Clara, California, USA
}

This study investigates an innovative method of avoiding brittle fracture at the beam-column connection welds of steel moment frames in earthquakes. The Reduced Web Section (RWS) approach introduces large openings into the web to shift the location of inelasticity away from the connections. The configuration of the openings governs the mode and capacity of inelastic mechanism in the beam. In this paper, experimental results are reported for five RWS specimens that were subjected to quasi-static cyclic loading. Four specimens were designed to develop Mode-A mechanisms; three had a single unique opening at midspan, and one had two openings near the beam-column connections. The other specimen was designed to develop a Mode-B mechanism without having web post buckling (observed in the Phase 1 specimens [1]), which had a wide opening and two brass plates clamped to the web. The application of web openings was successful in achieving the intended inelastic mechanisms; inelastic deformation was due to yielding, buckling, and/or fracture of the webs around the opening(s) and plastic hinging of the T-sections above and below the opening(s). The three specimens with a single opening at midspan exhibited the most stable load-drift responses; the specimens displayed a loss of strength during the 3 or $4 \%$ drift cycles (due to local buckling and/or fracture of the webs) and subsequent transition from "full" to "S-shaped" hysteretic loops, but they regained full strength by the end of testing at story drifts up to $7 \%$.

Keywords - Reduced web-section beam; Web opening; Beam-column connection; Steel moment frame; Seismic performance

*Address correspondence to Mark Aschheim, Department of Civil Engineering, Santa Clara University; 500 El Camino Real, Santa Clara, CA, 95053, USA; (E-mail) maschheim@ @scu.edu; (Phone) 1-408-554-6871; (Fax) 1-408-554-5474. 


\section{Introduction}

The unexpected fractures of steel beam-column connections in the Northridge and Hyogo-Ken Nambu Earthquakes in 1994 and 1995, respectively, have driven the development of a variety of approaches to improve connection performance $[2,3]$. Some methods focused on increasing the toughness of beam-column connections $[4,5]$, while others targeted reducing the intensity of stress concentration at the connections $[6,7]$. The latter typically involves the capacity design principle of shifting the location of inelasticity away from the beam-column connection by using haunches $[8,9,10]$ or by removing the flange portions near the connection (known as a "Reduced Beam Section") [11, 12] so as to induce yielding at the reduced section due to flexure.

In this study, an innovative approach is explored in which the shear strength of a wideflange section is reduced to induce yielding within the beam span due to shear and limit the stress level at the beam-column connection. Because steel beams of ordinary dimensions have ample shear strengths compared with shear demands, relatively large openings should be introduced in the web to generate yielding due to beam shear. This method has been termed "Reduced Web Section" in contrast to the more common approach in which the flanges are reduced, commonly described as a "Reduced Beam Section."

As part of comprehensive experimental and numerical investigations, ten wide-flange beam-column connection specimens were tested under lateral cyclic displacements in two phases. This paper discusses the seismic toughness and failure mechanisms of the five reduced web-section (RWS) specimens tested in Phase 2, as well as simple design formula and finite element analyses for the specimens. Design concepts for RWS beams subjected to earthquake loading and the seismic toughness and failure mechanisms of the five specimens tested in Phase 1 are discussed in the companion paper [1].

The primary design intent for the Phase 1 specimens was to limit inelastic deformation at the beam-column connections by providing significant inelastic deformation capacity through yielding around web openings located along the beam span. Although most specimens in Phase 1 showed a satisfactory performance with regard to the design intent, Specimens 2 to 5 experienced some degradation in lateral resistance due to the out-of-plane buckling of web posts [1]. The web post buckling was induced by the kinematics of the Mode-B mechanism that requires the shortening of web posts (Figure 1b). Therefore, the Phase 2 tests focused on investigating Mode-A mechanisms (Figure 1a), with the objectives of avoiding the loss of strength observed in Mode-B mechanisms and mobilizing additional strength owing to the strain 
hardening of T-sections above and below web openings.

\section{Derivation of Strength Design Formulae for Mode-A RWS Beams}

Figure 1 illustrates the two inelastic mechanisms that are assumed to develop in RWS beams. The Mode-A mechanism (Figure 1a) will occur when two plastic hinges form in each of the non-prismatic T-beams above and below the web opening. The Mode-B mechanism (Figure 1b) will occur when plastic hinges form in the web posts and in the T-sections above and below the opening located in the transition region. A detailed description of the Mode-B mechanism is provided in the companion paper [1]. Where it is unclear which mechanism may govern, the strength of each may be evaluated; the upper bound theorem of plastic analysis establishes that the weaker of the two calculated mechanism strengths is the governing mechanism.

Figure 2 illustrates static equilibrium for the top half of a beam (T-shape) having two symmetrically disposed perforations. The axial forces at the ends of the T-shape are equilibrated by horizontal shears along the mid-depth centerline of the beam. Figure 3 illustrates the variations of moment, shear, and axial force along the span of the T-shape when subjected to lateral forces due to wind or earthquake. There can be no shear flow between the top and bottom T-shapes at the location of a web opening. Thus, the axial force in the T-shape is constant in this region, while vertical beam shear is carried by flexure within the non-prismatic T-shapes above and below the opening. These effects, illustrated for a beam assumed to be weightless, are considered to be local departures from the overall moment, shear, and axial force diagrams.

The plastic moment strength at a T-section can be determined considering the expected axial compression or tension force (Figure 4). The ratio of plastic moment to yield moment can be on the order of 2 to 3 for T-sections, unlike doubly symmetric sections such as wide flanges for which this ratio is often in the range 1.15 to 1.20 . Furthermore, the strains in the web can be an order of magnitude greater than those in the flange, owing to the location of the plastic neutral axis within or near the flange. Consequently, an approximation for plastic moment strength $M_{T p}$ is suggested accounting for strain hardening as shown in Figure 5c. Two cases are considered as follows. If the plastic neutral axis is within the flange $\left(y_{P N A} \leq t_{f}\right)$, horizontal equilibrium of the plastified section requires:

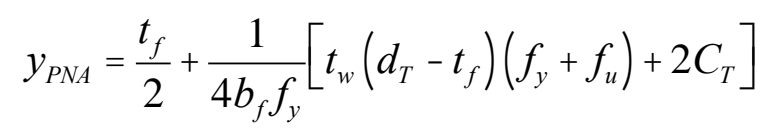

where $d_{T}$ is the depth of the T-section, $y_{P N A}$ is the depth to the plastic neutral axis from the extreme fiber of the flange, $t_{f}$ is the flange thickness, $b_{f}$ is the flange width, $t_{w}$ is the web 
thickness, and $C_{T}$ is the axial force (positive in compression) acting at the plastic neutral axis together with the moment $M_{T p}$ to cause compression in the flange. Thus, neglecting the possible minor influence of shear on the plastic moment capacity of the T-section, the plastic moment calculated about the geometric centroid of the T-section $\left(M_{T p}\right)$ is given by:

$$
M_{T p}=\frac{f_{y}}{2}\left[b_{f}\left(2 y_{P N A}\left(2 c-y_{P N A}\right)-t_{f}\left(2 c-t_{f}\right)\right)+\frac{t_{W}}{3}\left(d_{T}-t_{f}\right)\left(d_{T}+2 t_{f}-3 c\right)\right]+\frac{f_{u} t_{W}}{6}\left(d_{T}-t_{f}\right)\left(2 d_{T}+t_{f}-3 c\right)
$$

Alternatively, if the plastic neutral axis is within the web $\left(y_{P N A}>t_{f}\right)$, horizontal equilibrium requires:

$$
y_{P N A}=\frac{1}{t_{w}\left(3 f_{y}+f_{u}\right)}\left[2 t_{f}\left(t_{w} \quad b_{f}\right) f_{y}+2 C_{T}+t_{w}\left(f_{y}+f_{u}\right) d_{T}\right]
$$

with the corresponding plastic moment about the geometric centroid given by:

$$
M_{T D}=\frac{f_{y} b_{f}}{2} t_{f}\left(2 c-t_{f}\right)+\frac{f_{y} t_{W}}{6}\left[3\left(y_{P N A}-t_{f}\right)\left(2 c-y_{P N A}-t_{f}\right)+\left(d_{t}-y_{P N A}\right)\left(d_{t}+2 t_{P N A}-3 c\right)\right]+\frac{f_{u} t_{W}}{6}\left(d_{t}-y_{P N A}\right)\left(2 d_{t}+t_{P N A}-3 c\right)
$$

Equations (1) through (4) can be used to compute the conventional plastic moment strength by substituting $f_{y}$ for $f_{u}$ [13]. The shape of the axial load-moment interaction curve given by Equations 2 and 4 is illustrated in Figure 6 for perfectly plastic behavior, for a T-section formed by introducing a 16-in. (406-mm) diameter opening in a W21x68 shape.

The formation of a Mode-A mechanism requires four plastic hinges to form at a web opening, two in the T-beam above the opening and two in the T-beam below the opening. For purposes of initial proportioning, it is assumed that the plastic moment strength of a T-section can be calculated using Equations (1) through (4), neglecting the non-prismatic nature of the Tsection. If a symmetric opening is centered at a location of zero moment along the beam span, $C_{T}$ is equal to zero and the plastic moment strength $M_{T p}$ is identical in the four hinges. Since $M_{T p}$ is a function of $d_{T}$ which in turn is a function of position, the mechanism forms at the smallest shear $V_{b p}=4 M_{T p} / l_{T p}$ that can develop the four hinges, where $l_{T p}$ is the distance between the plastic hinges. The openings are proportioned so that the moment at the beam-column connection, $V_{b p}\left(L_{b} / 2\right)$, achieves the desired level of stress in the beam-column connection welds.

If the opening is not at a location of zero beam moment, the plastic moment $M_{T p}$ develops in the presence of axial compression or tension associated with the beam moment. Considering Figure 4, there are two unique cases. The hinges on the left side of the opening develop with axial and bending stresses at the extreme fiber superposing constructively; the compression and tension forces in the top and bottom $\mathrm{T}$-sections are identical in magnitude and 
differ only in sign. The hinges on the right side develop with axial and bending stresses at the extreme fiber opposing each other. For purposes of initial proportioning of the opening(s), it is assumed that principal stresses near the extreme fibers of any critical section of the T-beam are aligned almost parallel to the beam centerline to allow the section moment to be approximated using conventional plastic-section analysis. Thus, the non-prismatic nature of the T-beam is neglected during the initial proportioning. The beam moment $M_{b}$ is carried by a couple acting at the geometric centroids of the T-sections above and below the center of the opening. Thus, we estimate

$$
C_{T}=\frac{M_{b}}{d-2 \bar{y}}
$$

where $d$ is the depth of the entire beam section, and $\bar{y}$ is the depth from the extreme fiber to the geometric centroid of the central T-section.

One may proceed by first establishing the desired $V_{b p}$ to limit the moment at the beamcolumn connection (i.e. $V_{b p}\left(L_{b} / 2\right)$ ), to limit the stress in the beam-column connection welds to a desired level. Then, the beam moment at the center of the opening and associated axial force $C_{T}$ (Equation 5) are determined, and the opening details (e.g. size, shape) are determined to limit the beam shear to the desired $V_{b p}$. The axial force $C_{T}$ is assumed to be constant over the span of the T-beam. With reference to Figure 4, the value of $y_{P N A}$ for the plastic hinges at the left side of the opening is determined using a positive $C_{T}$ value in Equation 1 or 3, and $y_{P N A}$ at the right side is determined using a negative $C_{T}$ value. Values of $M_{T p}$ vary with position along the non-prismatic T-beam. The section at the left or right side of the opening that first develops $M_{T p}$ will be the one that requires the smallest shear. Due to the effect of $C_{T}$ on the value of $y_{P N A}$, the sections of plastic hinging at the left and right sides will be at different distances from the center of the opening. Since the mechanism requires all four hinges to develop, the mechanism strength is the value of $V_{b p}$ required to form the second pair of hinges.

Where two openings are located symmetrically about the midspan (e.g. Specimen 10), the $V_{b p}$ value determined for one opening is applicable to both; the second opening provides additional deformation capacity.

\section{Experimental Program}

In this study, ten approximately full-scale beam-column frame specimens were tested in two phases. This paper focuses on the five specimens tested in Phase 2, while a companion paper [1] focuses on those tested in Phase 1. The configuration of each frame specimen in Phase 2 (Figure 
6) was similar to that in Phase 1, comprising a wide-flange RWS beam with a unique web opening pattern, and a beam-column connection and stub column at each end of the beam. Based on the promising performance of Specimen 1 in Phase 1 [1], various web opening geometries (Figure 8) that would cause the Mode-A mechanism were mainly explored in Phase 2.

\subsection{Design of Phase 2 Specimens}

The Phase 2 tests focused on investigating Mode-A mechanisms (Figure 1a), with the objectives of avoiding the loss of strength observed in the Phase 1 specimens with Mode-B mechanisms due to the buckling of web posts, and mobilizing additional strength owing to the strain hardening of T-sections above and below web openings. Specimen 1 (Phase 1) that developed the Mode-A mechanism displayed a promising performance, although the test itself was not completed due to test hardware limitations [1].

Table 1 summarizes the design details and variables of the five Phase 2 specimens. The web opening geometries are illustrated in Figure 8. A W12×50 (Grade 50) shape was used for the beams in Specimens 6 to 8, and a W16×40 (Grade 50) shape was used for Specimens 9 and 10. Also, a W14×145 shape was used for the stub columns in all five specimens.

In Specimens 6, 7, and 8 (Figure 8), a single web opening at midspan was used to develop a Mode-A mechanism at midspan. For most applications, the RWS beams will have sufficient flexural and shear strengths for gravity loads acting over the beam span. When lateral loads are large enough, yielding will develop in the vicinity of the midspan opening due to shear. The midspan opening used in Specimens 6, 7, and 8 is at a location where beam shear due to gravity loads is nearly zero, and so yielding at this location is driven by lateral load beam shear. The plastic moment strength of the T-section above or below a web opening may be several (e.g. 2.5 to 3 ) times the yield moment strength. Thus, the plastification and strain hardening of the T-sections at the midspan zone may allow the beam to carry sufficient shear to then develop plastic hinges at or near the beam-column connections.

The performance of structural systems utilizing the inelastic mechanism of Specimens 6 to 8 is qualitatively similar to that of Special Truss Moment Resistant Frames [14], except that (1) the deformation capacity of a RWS beam is based on the geometry of the reduced wideflange section and (2) the system may develop a second mechanism involving plastic hinges near the beam-column connections at large drifts. Considering flexural deformations, the circular and elliptical web openings in Specimens 6 and 7 were determined to reduce the stiffness of a comparable unperforated $\mathrm{W} 12 \times 50$ beam by about $10 \%$. The central web post of Specimen 8 was devised to enhance the stiffness of the RWS beam under service-level lateral 
loads.

Specimen 9 (Figure ) aimed to develop an inelastic mechanism similar to that observed in Specimens 2 to 5. However, to avoid strength reduction associated with the buckling of web posts, Specimen 9 was designed to support a defined shear force between the top and bottom Tsections. This was achieved by detailing the beam to develop sliding friction between the web and two brass plates (Figure ), based on the work of Grigorian and Popov [15]. The contact surfaces between the web and brass plates were clamped by prestressed structural bolts that passed through the web of the beam; direct tension indicators (DTIs) were used to check the amount of pretension. Structural epoxy was used to attach the brass plates to the top T-section. Under service loads, the stiffness of the beam was expected to be similar to that of an unperforated W16×40 beam. Upon reaching a critical lateral load, the top and bottom T-sections were intended to slip against each other under an approximately constant shear force.

The design of Specimen 10 (Figure ) was similar to that of Specimen 1. Two circular web openings were provided near the beam-column connections. However, the two specimens were made of different steel shapes, and the opening diameter-to-beam depth ratio, $d$ '/d, in Specimen 10 was 0.66 compared with 0.78 for Specimen 1.

Specimens 1 and 10 have web openings near the connections. If used in buildings to support floor loads, the openings will generally be located at locations of non-zero gravity load shear. Deformations will concentrate around the opening in which seismic shears superpose constructively with gravity shears. Reversals of seismic loading will lead to both openings deforming in the direction of gravity shear. This ratcheting of deformations in one direction will lead to a residual deformed shape that may significantly increase post-earthquake repair costs. Nevertheless, the T-sections above and below the openings experience significant axial forces due to their locations relative to the beam moment diagram. Thus, the deformability of these specimens, containing two openings with T-sections subject to axial loads, could differ from that of Specimens 6 and 7, which had only a single web opening at midspan.

The beam-column connections in Phase 2 were detailed similar to those in Phase 1 (refer to the companion paper [1]), except that the web of the beam was welded to the flange of the column following the SAC guidelines for the WUF-W connection [16]. This was done to minimize the likelihood of connection failures that could pre-empt the development of the intended RWS mechanisms.

\subsection{Material Properties}

The W12×50 (Specimens 6 to 8) and W16×40 (Specimens 9 and 10) were each produced from a 
single heat. Two coupons were obtained from the flange and one was obtained from the web of an extra beam segment obtained for each heat. The test coupons were prepared following the same procedures used in Phase 1 [1].

The tension tests of the steel coupons were conducted following ASTM A370 [17]. Table 2 reports the results of the tension tests, and Table 3 shows the manufacturer's mill test data. All the properties summarized in Table 2, such as those related to yielding, strain hardening, and rupture, were determined following the same procedures used in the Phase 1 tests [1].

\subsection{Specimen Fabrication}

The specimens in Phase 2 were fabricated by Ozark Steel Fabricators, Inc. in Farmington, Missouri, USA, the same contractor as for the Phase 1 specimens. The web openings in the beams were cut using a Peddinghaus Corporation CNC Structural Steel Burning System and the same procedures used in Phase 1 [1].

\subsection{Test Setup and Loading Sequence}

The loading frame configuration is shown in Figure 6, which differed from that in the Phase 1 tests only in that a TS $1612 \times 5 / 8$ shape was used for the top beam. The H-shaped beam-stub column frame specimens had to fit within a clear distance of $4.11 \mathrm{~m}$ (161-3/4 in.). With the W14×145 stub columns, the beam clear span was $3.35 \mathrm{~m}$ (131-3/4 in.).

A reversed cyclic loading history (Figure ) conforming to the FEMA/SAC loading protocol [3] was applied quasi-statically by the actuator attached to the top beam, just as for the Phase 1 specimens. The story drift is defined as the actuator displacement divided by the vertical distance between the top and bottom pins. Note that story drifts in real buildings corresponding to a certain level of damage in the tested beams would be larger than the story drifts reported herein, because the loading frame and stub columns together created much stiffer elements than columns in real buildings.

\section{Preliminary Nonlinear Finite Element Analysis}

Preliminary finite element (FE) analyses were conducted using Abaqus/Standard software [18] for the five specimens as well as two unperforated control specimens (labeled "W12×50" and "W16 $\times 40 ")$ consisting of the same steel shape but lacking web openings. The analyses were done to confirm the intended inelastic mechanisms (Figure 1) and to estimate the specimen strengths. 
The RWS beam in Figure 6 was modeled with the boundary conditions and loading pattern that replicate the conditions of the experiment; both ends were restrained to prevent rotation while one end was displaced relative to the other end. The nominal specimen dimensions in Figure were used, and the clear span length between the faces of the stub columns was taken as $3350 \mathrm{~mm}$. The Abaqus element C3D20R (20-node quadratic solid element with reduced integration) was used throughout each model. A bilinear stress-strain relationship was assumed for the steel, with the yield strength of $379 \mathrm{MPa}(55 \mathrm{ksi})$, elastic modulus of 200 GPa (29,000 ksi), and post-yield (strain-hardening) modulus of $1.38 \mathrm{GPa}$ (200 ksi). At this stage, no attempt was made to simulate fracture.

Figure and 12 present the computed story shear-story drift responses of the RWS specimens from the FE analysis. Based on the geometry of the loading frame (Figure 6), the story shear is taken as 1.43 times the beam shear calculated by the FE analysis, and the story drift is taken as the beam chord rotation divided by 1.34 , in which the chord rotation is the transverse displacement divided by the clear span length of the beam. The results in Figure and 14 are obtained from the Abaqus models using large-deformation element formulations that take into account geometric nonlinearity (i.e., include large-displacement effects). In contrast, the results in Figure and 13 are from the models using small-deformation element formulations that ignore geometric nonlinearity.

The two models for each specimen produce very similar results at story drifts less than about $0.7 \%$ (Figure and 12), which includes the linear elastic range of response and some inelastic deformation. At larger drifts, however, the computed story shear-story drift response is influenced by consideration of geometric nonlinearity. Even at story drifts of approximately $1 \%$ to $2 \%$, a significant difference in response is evident for Specimen 7 . This is attributed to large local deformations in the vicinity of the opening, resulting in inclined forces that affect the statics in the deformed configuration.

The mechanism strengths, $V_{F E M}$, were determined at the point on the load-drift curve where the tangential slope changes abruptly. This point corresponds to about $1 \%$ drift in Specimens 6 and 10, and 1.5\% drift in Specimens 7 and 8 (Figure 12). The resulting strengths are provided in the last column of Table 1.

Beginning at story drifts of approximately 2 to $3 \%$, for the control (unperforated) beams and Specimens 6, 7, and 8, the computed story shear at a given drift is larger when geometric nonlinearity is taken into account, and this difference increases with increasing drift. This is attributed to the development of a tensile axial force in the beam (Figure c), associated with the kinematic requirement that the beam elongate with increasing story drift. This tensile force, 
when considered in the deformed configuration, contributes to the story shear resistance (Figure b). For Specimen 10, however, consideration of geometric nonlinearity results in a reduction in computed story shear at story drifts between approximately 1.5 and $5.5 \%$, followed by an increase in story shear at larger drifts. The reduction is attributed to more significant web buckling around the openings (i.e., large-displacement effects in compression) in this specimen than in Specimens 6 to 8; the openings in Specimen 10 were located farther away from the beam midspan and subjected to larger moments. The later increase in story shear resistance, delayed to story drifts exceeding approximately $5.5 \%$, is attributed to the tensile forces associated with the kinematic elongation of the beam, as for Specimens 6, 7, and 8 .

To better understand the tensile forces associated with kinematic elongation, Figure c plots the axial forces in the RWS beams obtained from the FE models including largedisplacement effects. A tension force clearly develops within the beams, and it increases with story drift. Among Specimens 6, 7, and 8, Specimen 7 develops the largest tension force at every step. The large tension force seems to confirm that statics in the deformed configuration provides resistance to story shear (Figure c) and hence explains the difference in the response of Specimen 7 in Figure and 12. No net tension force develops over the beam cross section in small-deformation analyses (Figure ), indicating a potential limitation of such analysis.

Figure 12(d) plots the ratio of lateral force determined considering geometric nonlinearity (Figures 12(a) and 12(b)) and that determined ignoring geometric nonlinearity (Figures 11(a) and 11(b)), as a function of story drift. It is apparent that second-order effects have a beneficial effect on the lateral resistance provided by RWS beams. The increase in strength developed with increasing story drift and was greatest for Specimen 7 (approximately $10 \%$ increase in strength at $4 \%$ story drift, and $20 \%$ at $7 \%$ story drift).

In Phase 2, the strength differences between the RWS and control specimens are much smaller than those in the Phase 1 specimens; for instance, the largest strength difference between Specimens 6 to 8 and the unperforated W12×50 is less than $22 \%$ at $1 \%$ story drift. Among the three W12×50 RWS beams, Specimen 6, having a circular opening, shows the largest stiffness and highest yield strength, while Specimen 7, having an elliptical opening, begins nonlinear load-drift behavior at an earlier drift and shows the lowest yield strength. Specimen 8 has a slightly higher stiffness than Specimen 7, considering the stiffness of the web post at midspan. However, the Abaqus model does not represent the fracture of the web post at high tensile strains.

Figure and 14 illustrate deformed shapes of the Phase 2 specimens at 5\% story drift from the FEM analyses, together with contours of maximum principal stress. Specimens 6, 7, 8, 
and 10 are predicted to go through failure modes associated with the Mode-A mechanism (Figure 1a). The sequence of damage involves yielding of the webs around the opening(s) followed by plastic hinging in the T-beams above and below the opening(s), and some yielding near the beam-column connections. The FE analysis indicates the Phase 2 specimens (other than Specimen 9) will experience some yielding at the beam-column connections unlike the Phase 1 specimens, although most of the inelastic deformation capacity will come from plastic hinging in the T-beams above and below the opening(s).

In contrast, Specimen 9 is expected to develop the Mode-B mechanism (Figure 1b). The specimen would likely undergo some slip along the defined friction plane, and yielding and plastic hinging at the deep web openings that define the ends of the wide flange T-sections. However, the FEM analysis of Specimen 9 is out of scope of this study due to the complexity of properly modeling slippage and friction.

Note that the monotonic FE models do not replicate buckling or fracture of the RWS beams, which greatly affected the performance of the specimens in the tests after the initial yielding and mechanism formation.

\section{Test Results}

\subsection{Inelastic Mechanism and Strength}

Photographs of the specimens in their deformed configurations near the end of testing are presented in Figure, except that no such picture is available for Specimen 6. All specimens developed the intended mechanisms. Specimens 6, 7, 8, and 10 developed the Mode-A mechanism of Figure 1a, while Specimen 9 developed an inelastic mechanism similar to ModeB in Figure 1b. The deformed shapes are similar to those predicted by the FE analyses (Figure ).

Figure shows cyclic story shear-story drift responses of the five RWS specimens, and the envelope curves constructed by connecting the maximum drift point of the first cycle to each drift level. Of the three specimens with one opening at midspan (consisting of a W12×50 shape), Specimen 6 sustained the largest load at every drift level in general, which corresponds with the FE analysis results. The non-prismatic T-beams formed above and below the opening in Specimen 6 had a shorter span length than those in Specimen 7, and a smaller cross section at the center of the opening. As a result, a plastic mechanism involving flexural hinging of the Tbeams in Specimen 6 developed at a larger beam shear. Specimen 9 had a much lower strength than Specimen 10 (both consisting of a W16×40 shape), which primarily resulted from intended slip on the surfaces of the brass plates clamped to the web. Different strength levels during the 
slip were obtained by changing the tension on the bolts that provided a clamping force across the frictional interfaces.

The yield point in the experimental load-drift curve is defined conventionally as the intersection point between the secant of the envelope curve from the origin to the point of $75 \%$ the maximum load and the horizontal line passing through the maximum-load point (ATC 24 [19]). Table 4 shows story shears and story drifts at the yield and maximum-load points in each test. In the early range up to the yield point, Specimen 10 showed the highest stiffness; its stiffness at the yield point was about 35\% larger than the second highest stiffness of Specimen 6 . In contrast, Specimen 7 showed the lowest stiffness among the Mode-A specimens, and the yield point was at about $2.54 \%$ drift.

Table 5 compares the average of the measured maximum loads, $V_{\text {exp,avg }}$ (averaged for positive and negative sides) for Specimens 6, 7, and 10 (having circular or elliptical openings) with the story shear $\left(V_{c p}\right)$ calculated based on the assumed plastic mechanism (using Eqs. (1) to (5)) either considering strain hardening (SH) or perfectly plastic (PP) assumptions. The calculation makes use of the original, undeformed geometry for dimensions and directions of forces, and thus is referred to as a first-order mechanism strength. The average maximum strengths were bounded by the first-order PP and SH strengths; a comparison with the average of the first order strengths, $V_{c p \text {, avg }}$ resulted in ratios of $V_{\text {exp, avg }} / V_{c p \text {, avg }}$ of between 1.01 and 1.09 . The last row of Table 5 compares nominal mechanism strengths determined by monotonic finite element analysis, $V_{F E M}$, with the average of the first-order PP and $\mathrm{SH}$ strengths, $V_{c p \text {, avg. }}$ Ratios $V_{F E M} / V_{c p \text {, avg }}$ ranged between 0.91 and 0.98 , indicating that the strain hardening did not develop to the extent implied by the average of the first order PP and SH strengths, at the point of nominal mechanism development in the finite element analyses.

\subsection{Overall Load-Displacement Response}

Specimen 6 showed essentially elastic behavior up to $0.75 \%$ story drift (Figure ). The specimen exhibited stable and full hysteretic responses through the first cycle to $3 \%$ drift. During the second cycle to $+3 \%$ drift, the load suddenly dropped by about $40 \%$ due to brittle fracture of the web around the opening; additional fractures around the opening followed in the first cycle to $4 \%$ drift. Of note, the load quickly recovered and was maintained by the end of testing, so that the maximum load in the $4 \%$ drift cycles was similar to that in prior cycles. After the web fractures, the cyclic load-drift loops became "S"-shaped with pinching around the position of zero displacement. It should be noted that the actuator capacity in the pull (+) direction was limited to about 95 kips, and this is less than the push (-) capacity. Thus, the actuator stalled out 
at a maximum drift of about $4 \%$ in the pull (+) direction, while the specimen was pushed to drifts of $-7 \%$.

Specimen 7 began to develop nonlinearity in the load-drift response at a smaller story drift (approximately 0.5\%) compared with the other specimens. Also, the nonlinear behavior in the test initiated at a smaller drift and under a lower load than in the FE model (Figure ). During the $2 \%$ drift cycles, fan-shaped bands of yielding (Figure ) became visible at the sides of the web opening. However, the lateral load increased gradually, and at $4 \%$ drift reached about $94.8 \%$ of the value estimated by the FE model. Specimen 7 maintained full load-drift hysteresis loops up through the first $4 \%$ drift cycle. Brittle fractures occurred successively at the corners of the web opening (Figure ) from the second cycle to $+4 \%$ drift through the first $5 \%$ drift cycle; the web crack at the 2 o'clock position of the opening extended to and along the web-flange intersection through ductile tearing from 5\% drift. The brittle web fractures caused sudden strength drops and changed the shape of the load-drift curves to be pinched. However, as with Specimen 6, the strength of Specimen 7 fully recovered during the 6\% drift cycles, and was maintained through the end of testing.

In Specimen 8, the web post between the two openings at midspan fractured during the $1.5 \%$ drift cycles. After the center web post fractured, the nonlinearity of the load-drift response became significant. This nonlinear behavior developed at a much lower load than that estimated in the FE model, because fracture was not represented in the model. The narrow web portions between the openings and flanges buckled out-of-plane during the $2 \%$ drift cycles, and they experienced brittle fractures (Figure ) during the first 3\% drift cycle. The cracks caused by the brittle fractures were subjected to subsequent ductile tearing along the web-flange intersections from $4 \%$ drift. The web fractures significantly reduced the strength of the specimen, and caused the load-drift curves to become severely pinched and "S"-shaped. However, as the story drift increased from $4 \%$ to $7 \%$, the specimen strength continued to increase and reached over $450 \mathrm{kN}$ (101 kips). Note that the test was stalled at about 6\% drift in the pull (+) direction because of the limited actuator load capacity.

Nonlinearity in the load-drift response of Specimen 9 was evident beginning with the $0.75 \%$ drift cycles, when the brass plates on both sides of the web began to slip. Due to the slippage, the load-drift curves came to be saw-tooth shaped with little strength increase afterward. The saw-tooth character reflects flexibility in the frame; that is, slippage resulted in a reduction of load, which could be recovered only by imposing further displacement, until a sufficient load was present to initiate further slip. Displacement control of the actuator required rapid changes in the hydraulic pressure, resulting in something akin to a jack-hammer effect. For 
this reason, the bolts applying clamping pressure across the friction interface were loosened. While this reduced the slip load, the hammering effect was still present, and further reductions in bolt tension were made. During the $3 \%$ drift cycles, minor web buckling occurred at the top of the right opening and the bottom of the left opening. It was during the first $4 \%$ drift cycle that large strength drops occurred and the load-drift curves became almost flat. This occurred when the webs at the top of the right and the bottom of the left opening suffered brittle fractures (Figure ). At 5\% story drift, brittle web fractures also occurred at the bottom of the right and the top of the left opening. The cracks from the brittle fractures extended to and along the webflange intersections by ductile tearing during the 6 and $7 \%$ drift cycles.

Specimen 10, which had two web openings, each located close to a beam-column connection, exhibited essentially elastic behavior up to about $1 \%$ story drift. During the first cycle to $2 \%$ drift, the webs at the right opening (roughly 2 and 8 o'clock positions) fractured in a brittle manner, and the T-beams above and below this opening buckled (Figure ). This resulted in a significant strength drop; the maximum load in the second cycle to $2 \%$ drift was less than $50 \%$ of that in the first cycle. The cracks caused by the brittle fractures extended to and along the web-flange intersections by subsequent ductile tearing from $2 \%$ drift. As Specimen 10 was loaded in the $3 \%$ to $4 \%$ drift cycles, the strength increased gradually, but the load-drift loops became severely pinched near the position of zero displacement. Another major strength drop occurred during the first 5\% drift cycle due to buckling of the T-beams above and below the left opening as well as brittle fractures of the webs around it (roughly 4 and 10 o'clock positions).

\subsection{Strains at Web Openings and Beam-Column Connections}

Figure 17 illustrates locations and numbering of electrical resistance strain gages. Table 6 summarizes the approximate story drift at which each portion of the specimen began to yield, based on data obtained from electrical resistance strain gages. In all specimens except Specimen 8 , the first yielding occurred in the webs around the opening(s) at about 0.75 to $1 \%$ drift; the web post in Specimen 8 yielded at $0.25 \%$ drift. In the Mode-A specimens, yielding spread over the flanges near the connections at about 1.5 to $2 \%$ drift, while Specimen 9 showed no yielding near the connections by the end. No specimen experienced yielding at flanges and webs away from the connections or midspan.

\subsection{Effects of opening details}

The Mode-A specimens attained a resurrection of strength from about 4 or $5 \%$ drift. The regain of strength at these drift levels is likely attributed to strain hardening of the T-sections at the 
openings and/or geometric second-order (large deformation) effects; beneficial effects of geometric nonlinearity are demonstrated in the FEM results. The mobilization of this strength revival would enhance the resistance of RWS beams against rare or unexpected intensities of ground motions by providing a reserve capacity.

Among the Mode-A specimens, Specimens 6 to 8 with a single opening at midspan exhibited more stable load-drift behaviors than Specimen 10 with two openings near the connections. The strengths of the three specimens increased by the end of testing up to $7 \%$ story drift, although they endured strength drops during the 3 or $4 \%$ drift cycles due to local buckling and/or fracture of the webs like the other specimens. In contrast, Specimen 10 suffered another major strength drop during the 5\% drift cycles due to buckling of the T-beams at the left opening and fracture of the webs around it.

Comparing the specimens with two web openings near the beam-column connections, Specimen 10 experienced yielding near the connections, while Specimen 1 did not. The web openings of Specimen 10 have a smaller $d$ '/d value and are located in regions of slightly smaller moment compared with those of Specimen 1.

\section{Conclusions}

From the experimental, analytical and numerical investigations of the Phase 2 specimens detailed herein, significant findings and conclusions are summarized as follows:

- The application of web openings was successful in achieving the intended inelastic mechanisms (Mode-A or Mode-B) of the specimens. The inelastic mechanisms and strengths of the specimens observed in the tests matched well with those predicted by monotonic nonlinear FE analyses.

- In all specimens, inelastic deformation and damage was predominantly due to yielding, buckling, and/or fracture of the webs around the opening(s), and plastic hinging of the T-sections above and below the opening(s). The first yielding occurred at about 0.75 to $1 \%$ drift in all specimens.

- Specimens 6, 7, 8, and 10, having Mode-A mechanisms, suffered some yielding near the beam-column connections, but no apparent damage was observed at or around the connections. In contrast, Specimen 9 with a Mode-B mechanism did not experience yielding near the connections.

- All specimens suffered strength drops due to buckling and fracture of the webs and/or T-sections around the opening(s). A major strength drop occurred during 4\%, 
$4 \sim 5 \%, 3 \%, 4 \%$, and 2\% drift cycles in Specimens 6, 7, 8, 9, and 10, respectively. This changed the typical pattern of load-drift hysteretic responses from full curves to S-shaped curves.

- The Mode-A specimens demonstrated a resurrection of strength from about 4 or 5\% drift, owing to strain hardening of the T-sections at the openings and/or geometric second-order (large deformation) effects. The mobilization of this strength revival would enhance the resistance of RWS beams against rare or unexpected intensities of ground motions by providing a reserve capacity.

- Among the Mode-A specimens, Specimens 6 to 8 with a single opening at midspan exhibited more stable load-drift behaviors than Specimen 10 with two openings near the connections. The strengths of Specimens 6 to 8 increased by the end of testing up to $7 \%$ story drift, although they endured strength drops during 3 or $4 \%$ drift cycles due to local buckling and/or fracture of the webs like the other specimens.

- The average of the peak experimental strengths (in the positive and negative directions of loading) was between 1 and $9 \%$ greater than that predicted using simple analytical formulae $\left(V_{c p}\right.$, avg $)$. Such formulae can be used to design web openings to achieve desired mechanisms for specimens with circular or elliptical web openings.

- Nonlinear FE analyses were useful for validating the experimentally observed inelastic mechanisms. Nominal mechanism strengths appeared to involve less strain hardening than assumed in the calculation of $V_{c p, \text { avg }}$.

\section{Acknowledgements}

The authors are grateful to Mr. Reid Sensescu, who previously compiled test data and contributed to an earlier discussion, as well as B. Dodds, J. Gambill, and W. Gordon, whose generous assistance proved invaluable, and are grateful for the use of facilities at the Construction Engineering Research Laboratory (Champaign, Illinois) under the adroit direction of J. Hayes. This work was primarily supported by the National Science Foundation under Grant No. CMS-9812465. Additional support from the Basic Science Research Program through the National Research Foundation of Korea (NRF), funded by the Korean Ministry of Education (Grant No. 2015R1D1A1A09061167), is also appreciated. Any opinions, findings and conclusions or recommendations expressed in this material are those of the authors and do not necessarily reflect those of the sponsor or the individuals or institutions identified above. 


\section{References}

1. Shin, M., Kim, S.-P., Halterman, A., and Aschheim, M. (in review). Seismic toughness and failure mechanisms of reduced web-section beams: Phase 1 tests. Engineering Structures, revised and resubmitted in MarchFebruary, $2016 \underline{\underline{2017}}$.

2. Federal Emergency Management Agency (FEMA). (2000). Recommended seismic design criteria for new steel moment frame buildings. Federal Emergency Management Agency, Washington, DC.

3. SAC Joint Venture. (2000). Recommended seismic evaluation and upgrade criteria for welded steel moment frame buildings (FEMA 351). Federal Emergency Management Agency, Washington, DC.

4. Chen, S. J., Yeh, C. H., \& Chu, J. M. (1996). Ductile steel beam-to-column connections for seismic resistance. Journal of Structural Engineering, 122(11), 1292-1299.

5. Civjan, S. A., Engelhardt, M. D., \& Gross, J. L. (2000). Retrofit of pre-Northridge moment-resisting connections. Journal of Structural Engineering, 126(4), 445-452.

6. Pachoumis, D. T., Galoussis, E. G., Kalfas, C. N., \& Christitsas, A. D. (2009). Reduced beam section moment connections subjected to cyclic loading: Experimental analysis and FEM simulation. Engineering Structures, 31(1), 216-223.

7. Shen, J., Kitjasateanphun, T., \& Srivanich, W. (2000). Seismic performance of steel moment frames with reduced beam sections. Engineering Structures, 22(8), 968-983.

8. Engelhardt, M. D., \& Sabol, T. A. (1998). Reinforcing of steel moment connections with cover plates: benefits and limitations. Engineering Structures, 20(4), 510-520.

9. Uang, C. M., Bondad, D., \& Lee, C. H. (1998). Cyclic performance of haunch repaired steel moment connections: experimental testing and analytical modeling. Engineering Structures, 20(4), 552-561.

10. Uang, C. M., \& Bondad, D. M. (1996). Static cyclic testing of pre-Northridge and haunch repaired steel moment connections (Vol. 96, No. 2). Division of Structural Engineering, University of California, San Diego.

11. Chi, B., \& Uang, C. M. (2002). Cyclic response and design recommendations of reduced beam section moment connections with deep columns. Journal of Structural Engineering, 128(4), 464-473.

12. Jones, S. L., Fry, G. T., \& Engelhardt, M. D. (2002). Experimental evaluation of cyclically loaded reduced beam section moment connections. Journal of Structural Engineering, $128(4), 441-451$. 
13. Moy, S. S. J. (1981). Plastic Methods for Steel and Concrete Structures. John Wiley \& Sons, New York, USA.

14. Goel, S. C., \& Itani, A. M. (1994). Seismic-resistant special truss-moment frames. Journal of Structural Engineering, 120(6), 1781-1797.

15. Grigorian, C. E., Yang, T. S., \& Popov, E. P. (1993). Slotted bolted connection energy dissipators. Earthquake Spectra, 9(3), 491-504.

16. SAC Joint Venture. (2000). Recommended seismic design criteria for new steel moment frame buildings. Rep. No. FEMA 350. FEMA, Washington, DC.

17. ASTM Standard A370. (2000). Standard Test Methods for Mechanical Testing of Steel Product.

18. Dassault Systemes. (2015). ABAQUS 6.14 Documentation, Simulia Co., Providence, RI, USA.

19. ATC-24. (1992). Guidelines for Cyclic Seismic Testing of Components of Steel Structures for Buildings. 


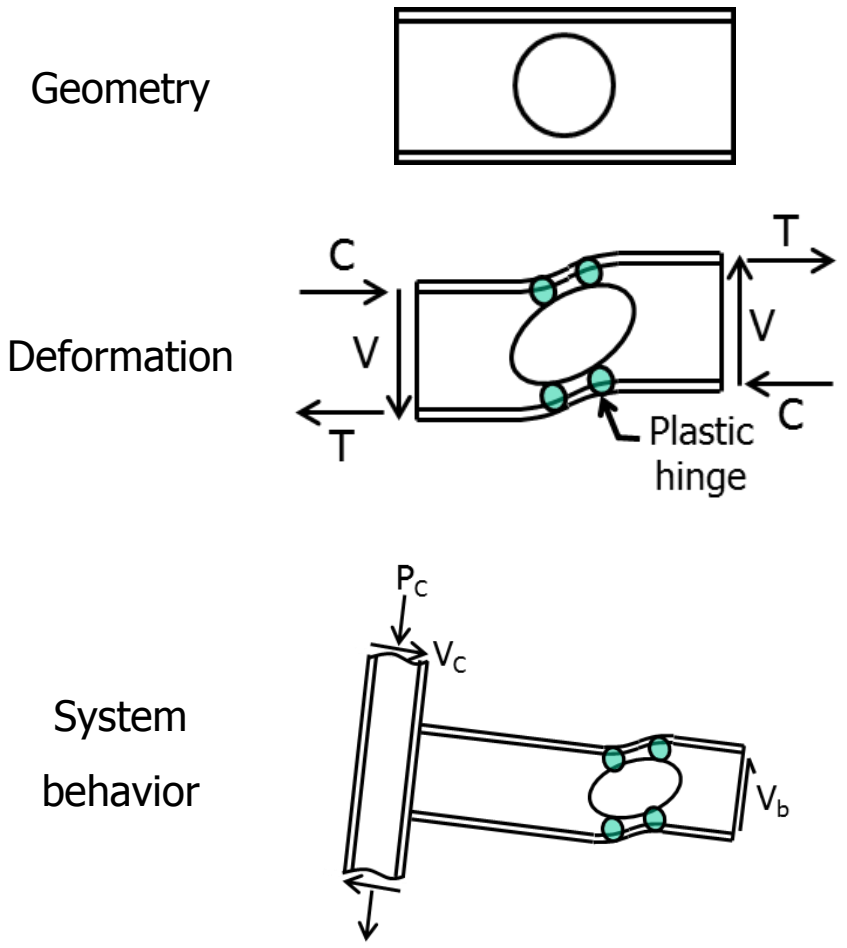

(a) Mode-A
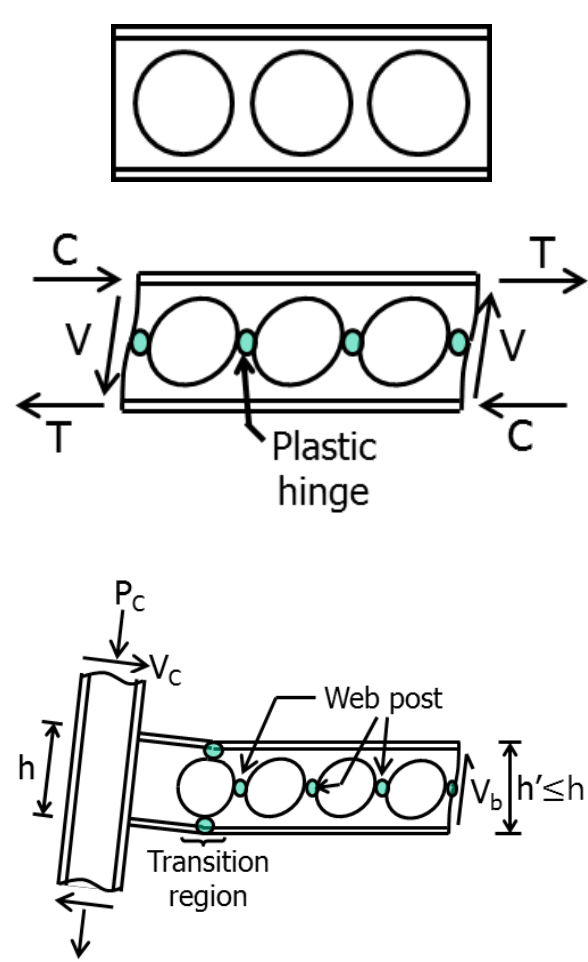

(b) Mode-B

Figure 1 - Inelastic mechanisms and deformations of reduced web-section beams $\left(h^{\prime}=\right.$ height of deformed beam, $\mathrm{h}=$ height of original beam)

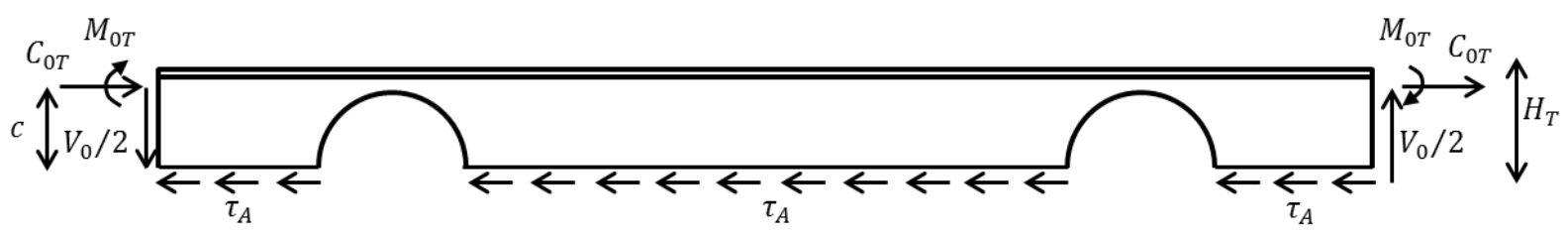

Figure 2 - Free-body diagram for the top half of a beam subjected to equivalent end forces at the geometric centroid, neglecting self weight. 


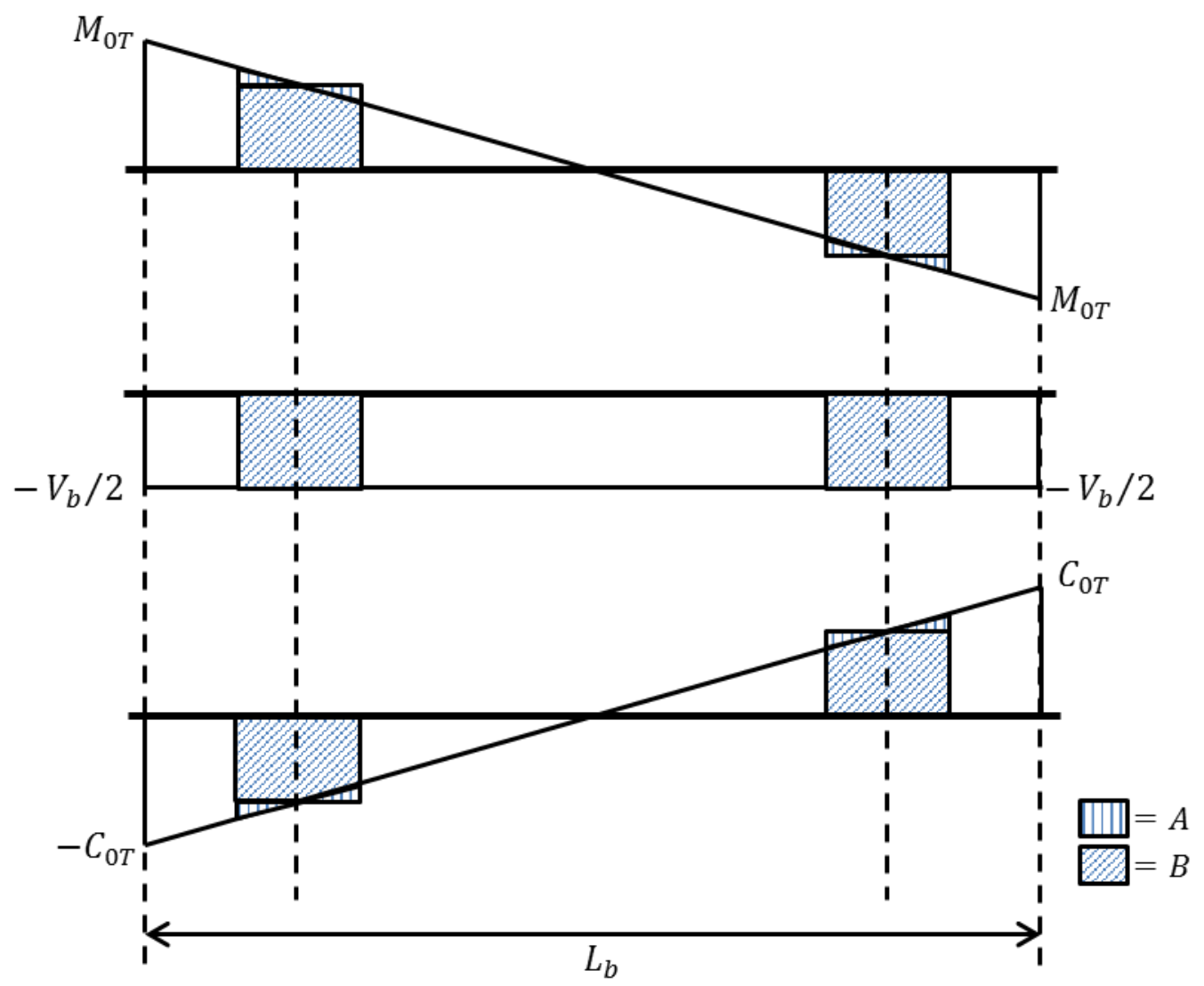

Figure 3 - Adjustments to the beam moment, shear, and axial force diagrams to account for the presence of an opening interfering with shear flow, for the top half of a beam with two openings

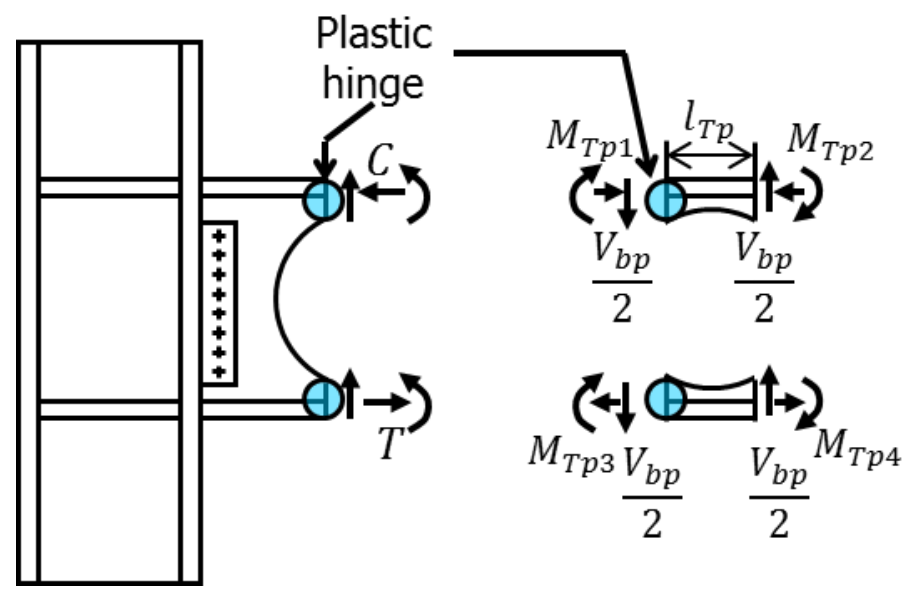

Figure 4 - Free-body diagrams of T-beams above and below an opening in a RWS beam with two openings 


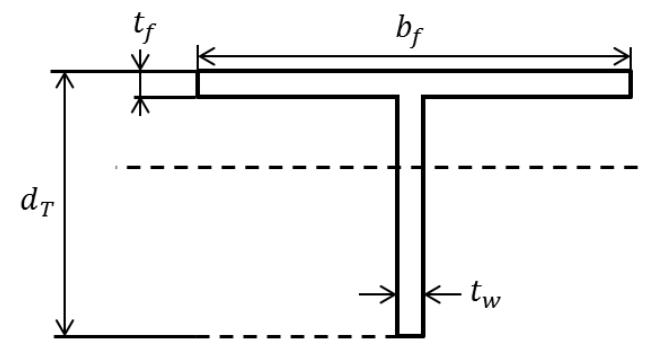

(a)

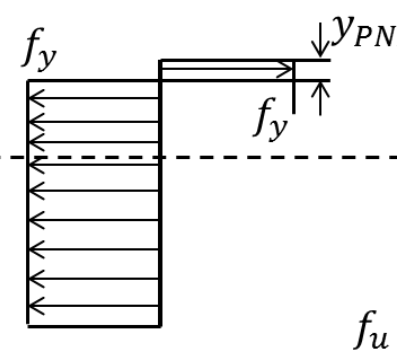

(b)

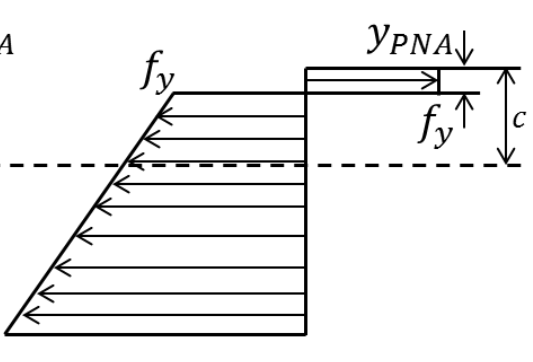

(c)

Figure 5 - (a) T-section at an opening, (b) normal stress distribution for conventional plastic analysis, (c) normal stress distribution with strain hardening for plastic moment $M_{T p}$

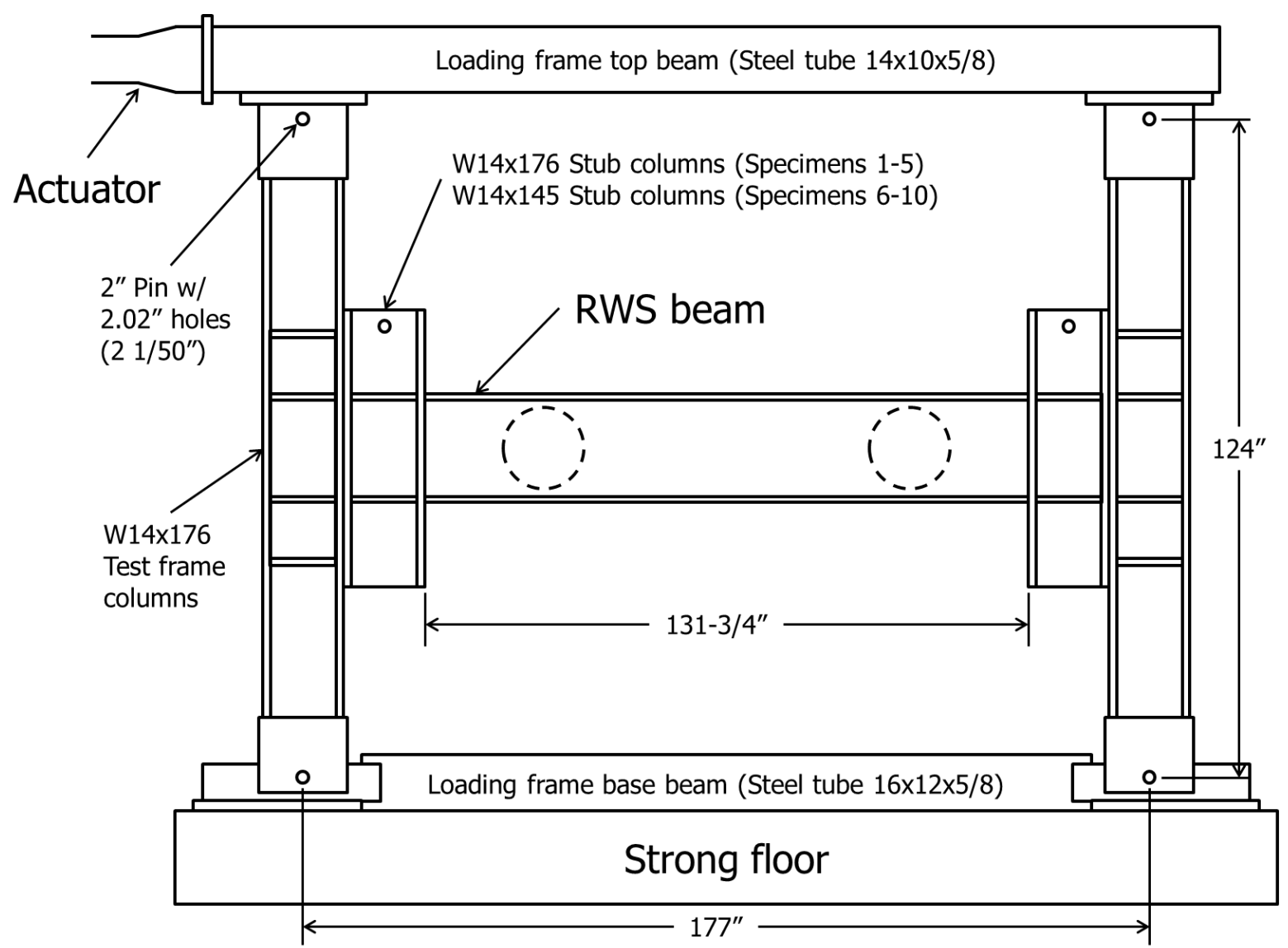

Figure 6 - Test setup and overall specimen dimensions in Phase $2(1$ inch $=25.4 \mathrm{~mm})$ 


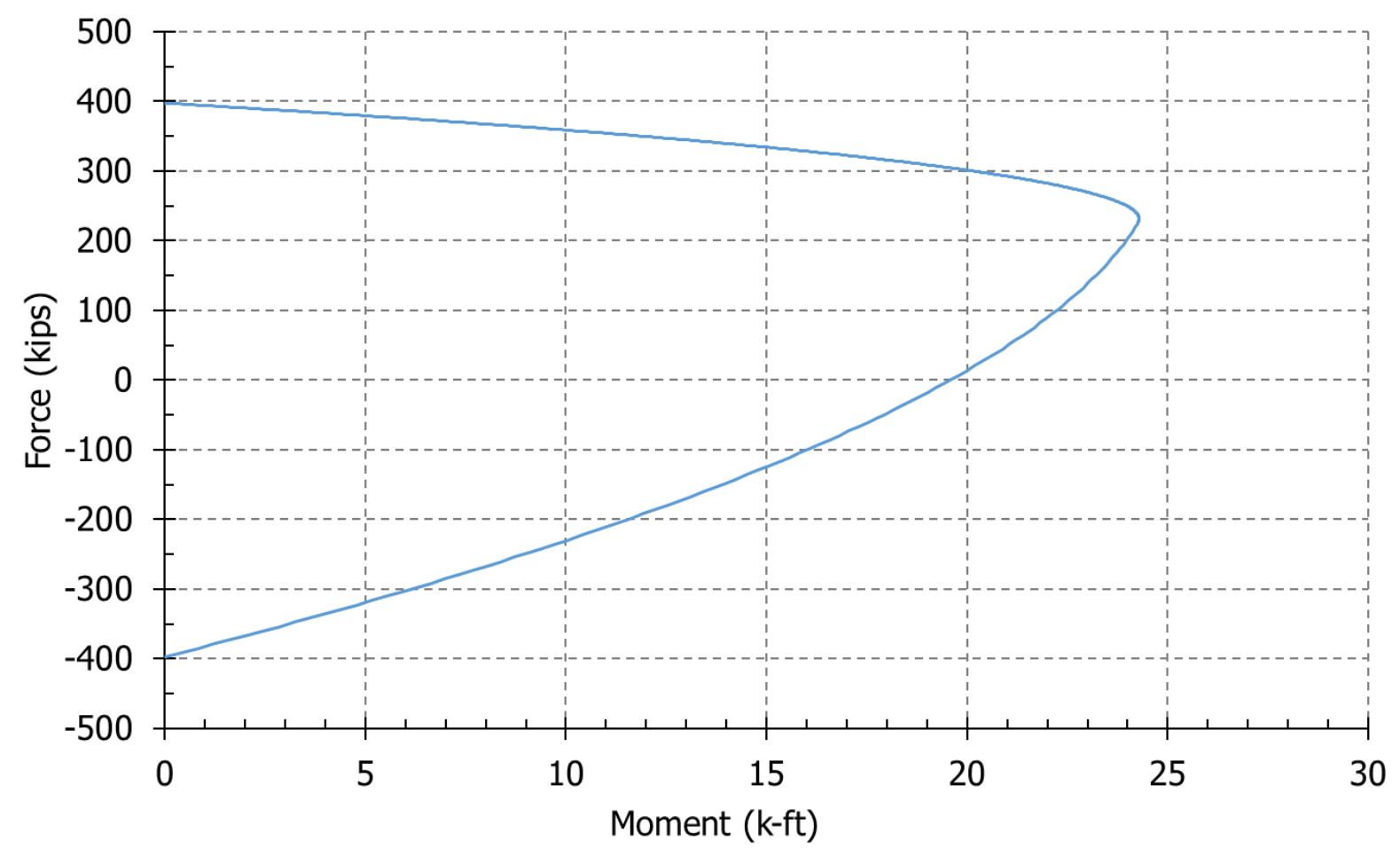

Figure 7 - Axial load-moment interaction for plastic conditions $\left(f_{y}=f_{u}=55 \mathrm{ksi}=379 \mathrm{MPa}\right)$ at a section 5-in. (127-mm) away from the center of a 16-in (406-mm) diameter hole in a W21x68 shape. 


\section{Specimen 6 (W12x50)}

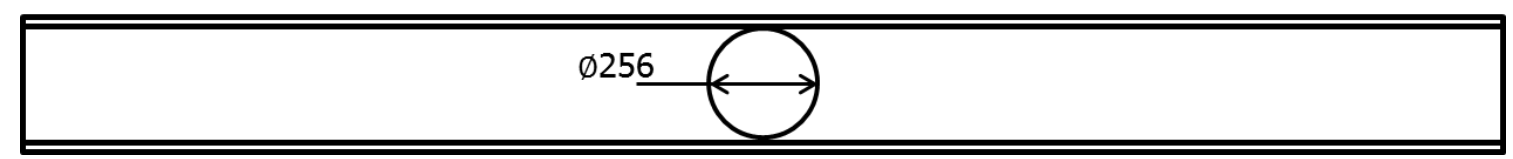

Specimen 7 (W12×50)

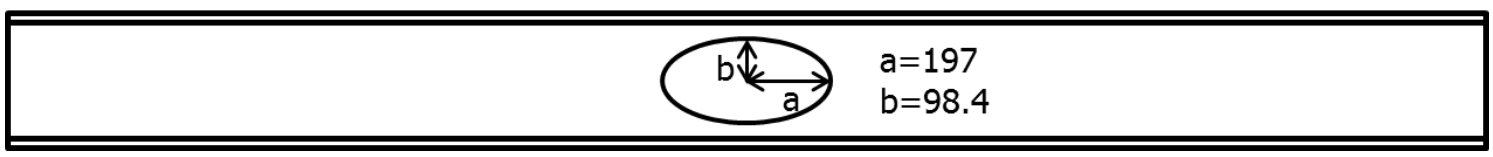

Specimen 8 (W12x50)

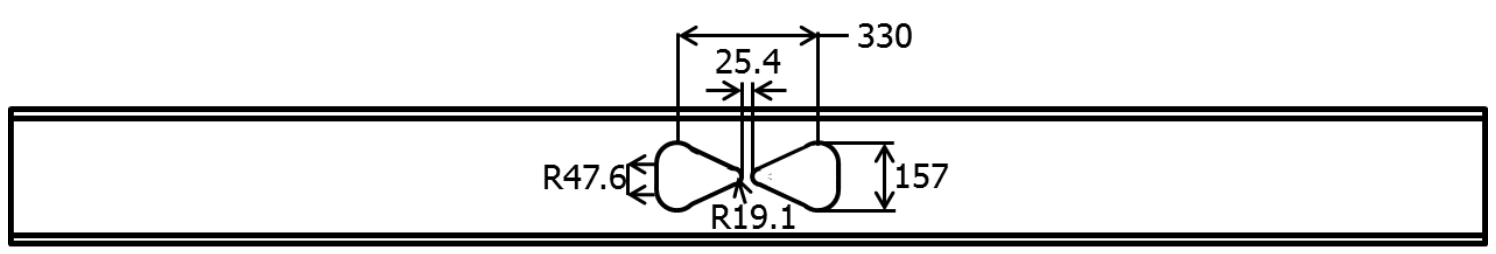

Specimen 9 (W16x40)

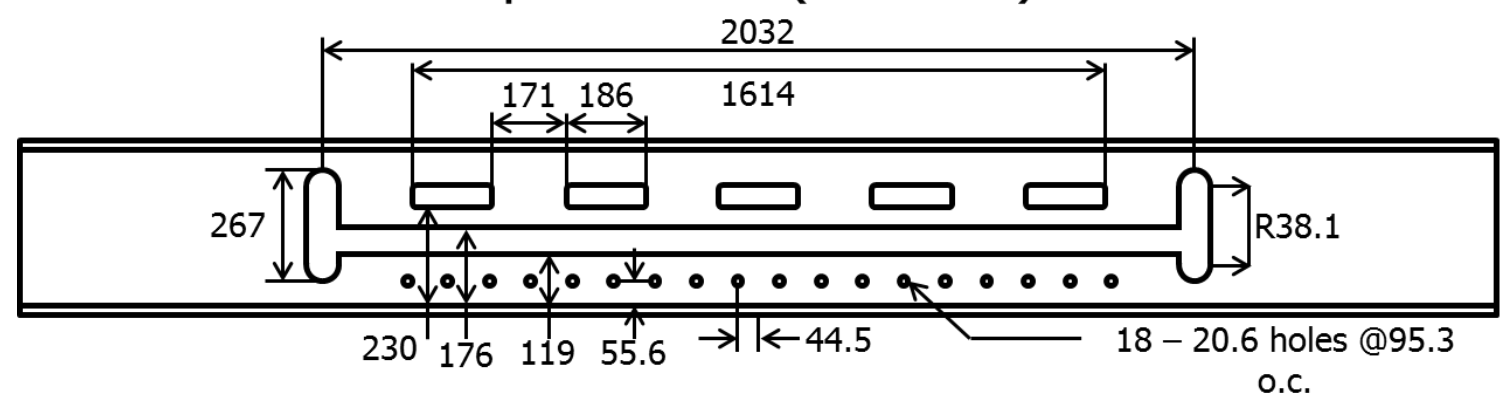

Specimen 10 (W16x40)

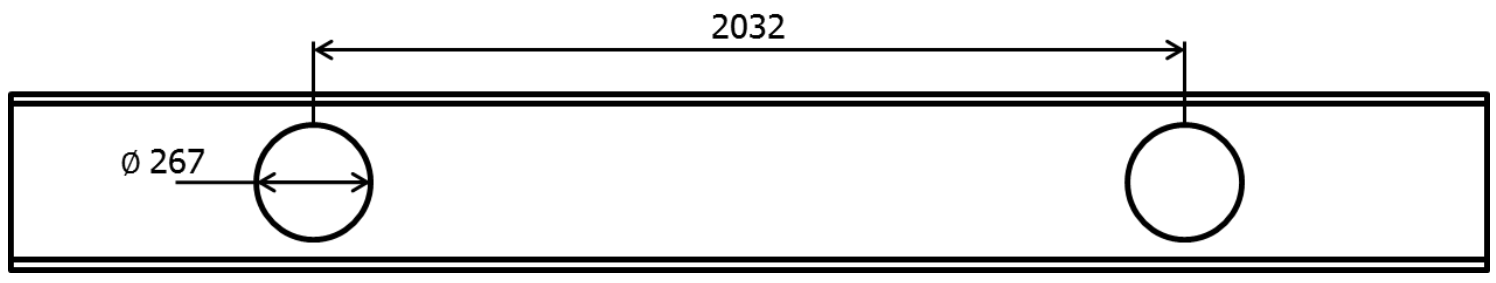

Figure 8 - Web opening geometries in Phase 2 specimens (units: $\mathrm{mm}$ ) 

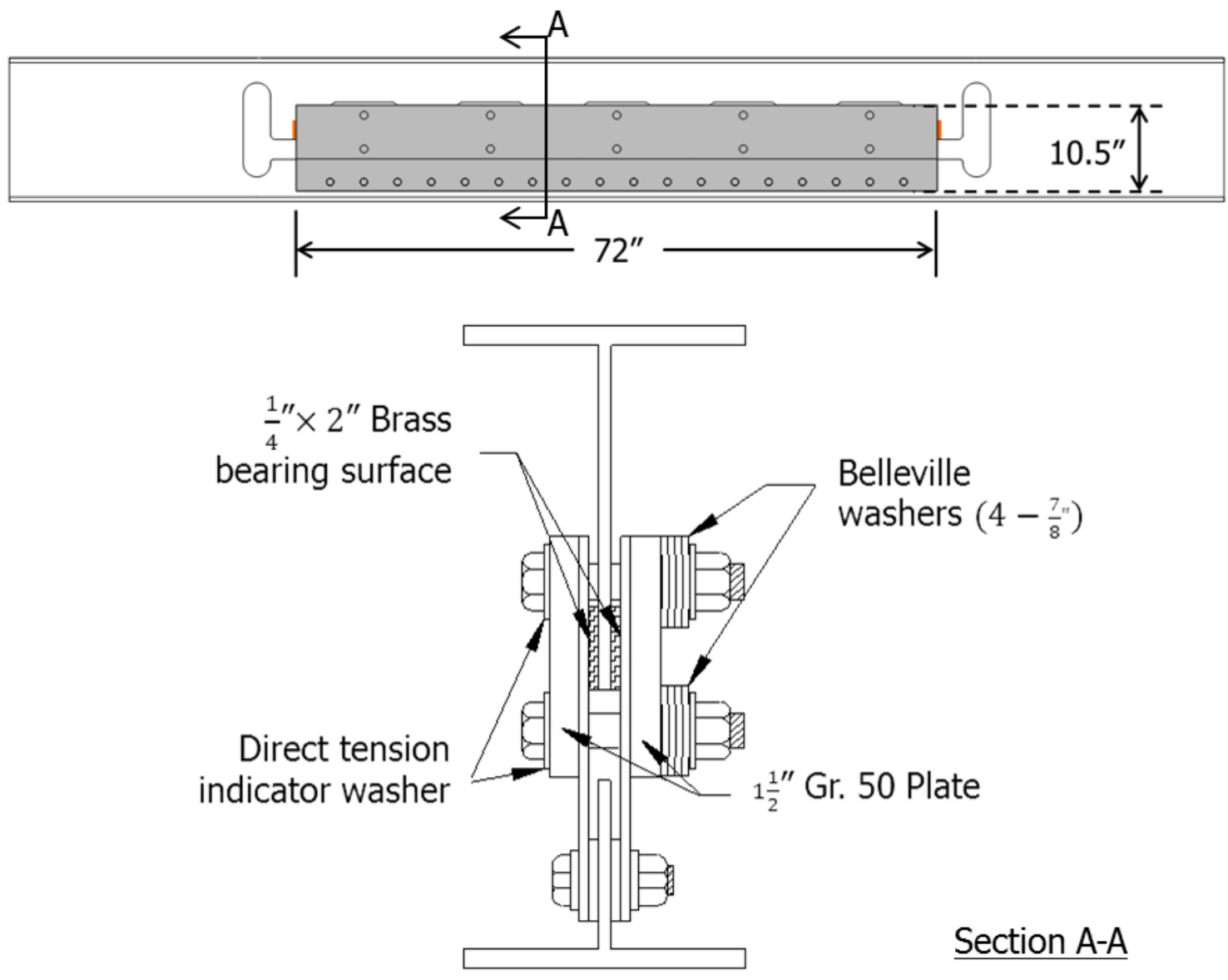

Figure 9 - Details for web-to-brass plate connections in Specimen $9(1 \mathrm{inch}=25.4 \mathrm{~mm})$

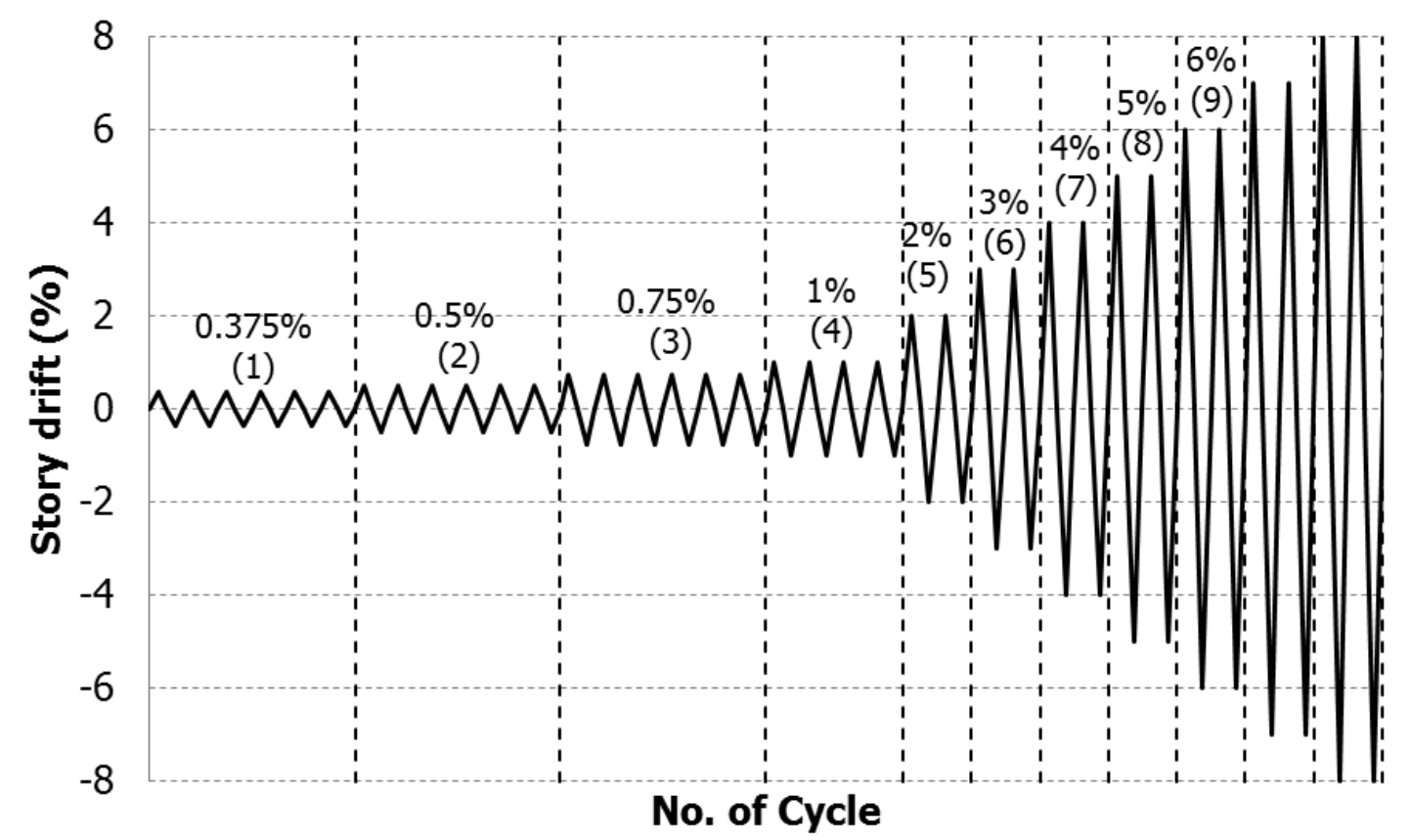

Figure 10 - Loading history. (Note that the "cycle number" provided in parentheses is used to reference strain gage data in Figures 17 through 21.) 


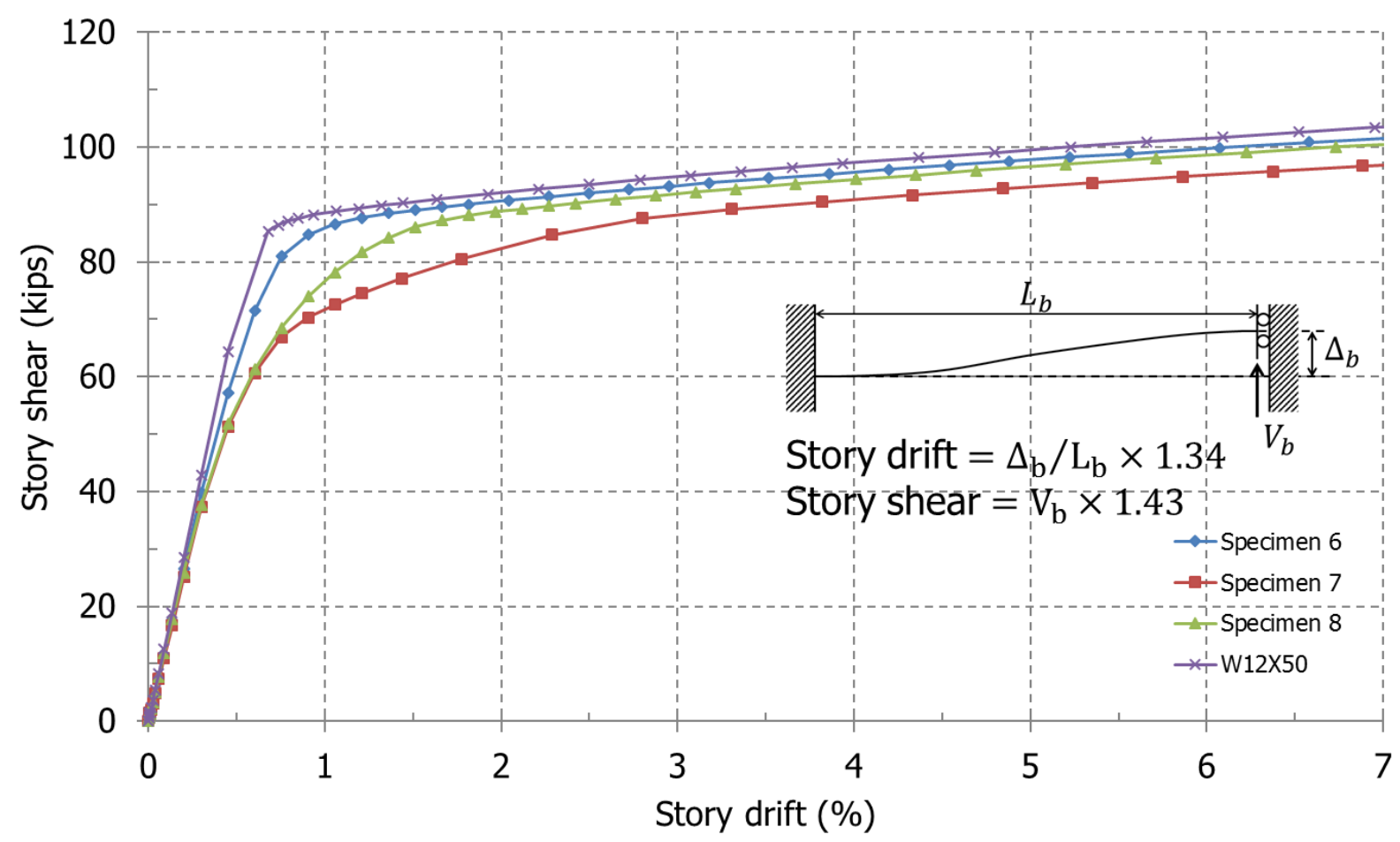

(a) Specimens made of $\mathrm{W} 12 \times 50$

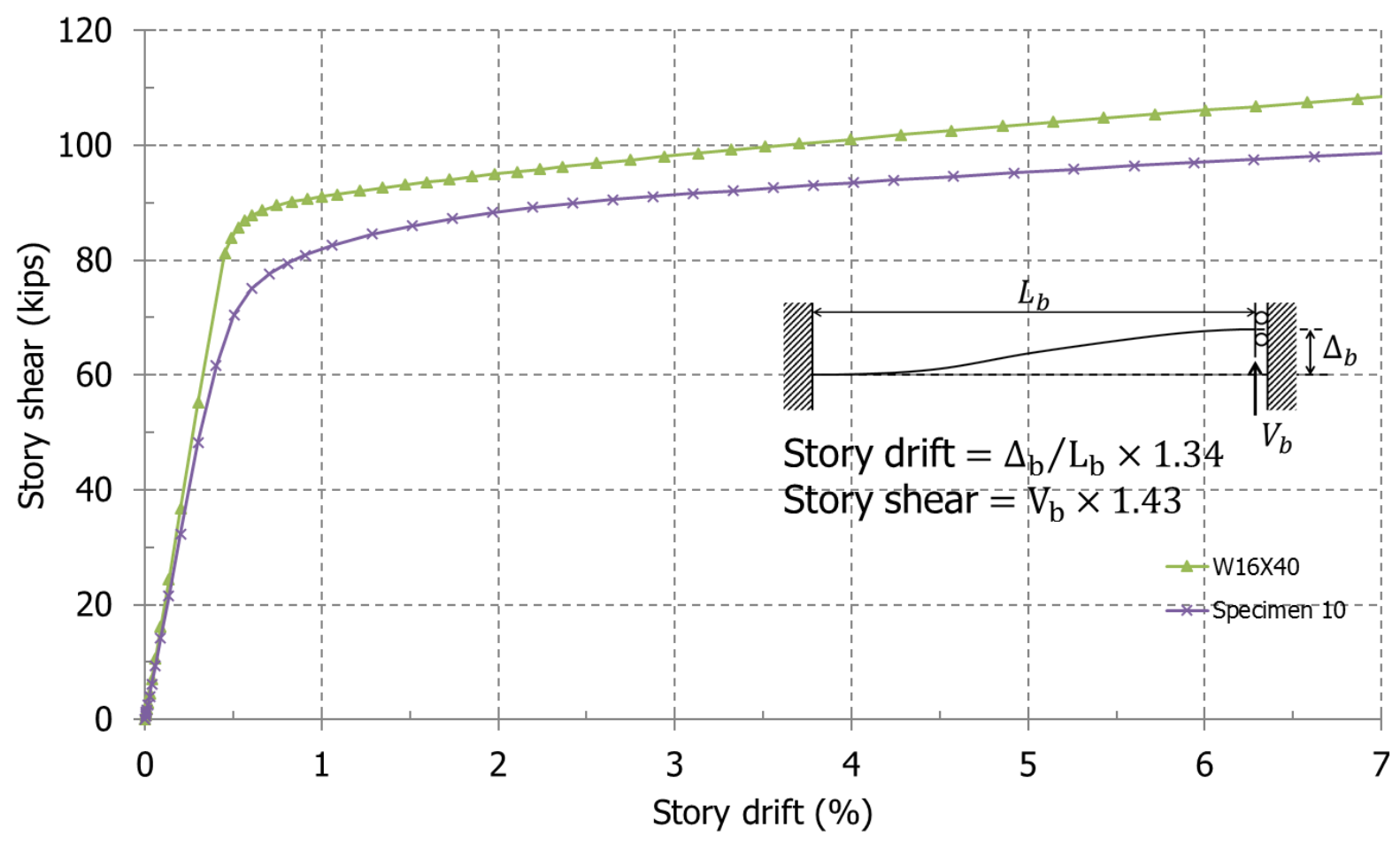

(b) Specimens made of $\mathrm{W} 16 \mathrm{x} 40$

Figure 11 - Nonlinear finite element analysis results without accounting for geometric nonlinearity for Phase 2 specimens $(1 \mathrm{kip}=4.45 \mathrm{kN})$ 


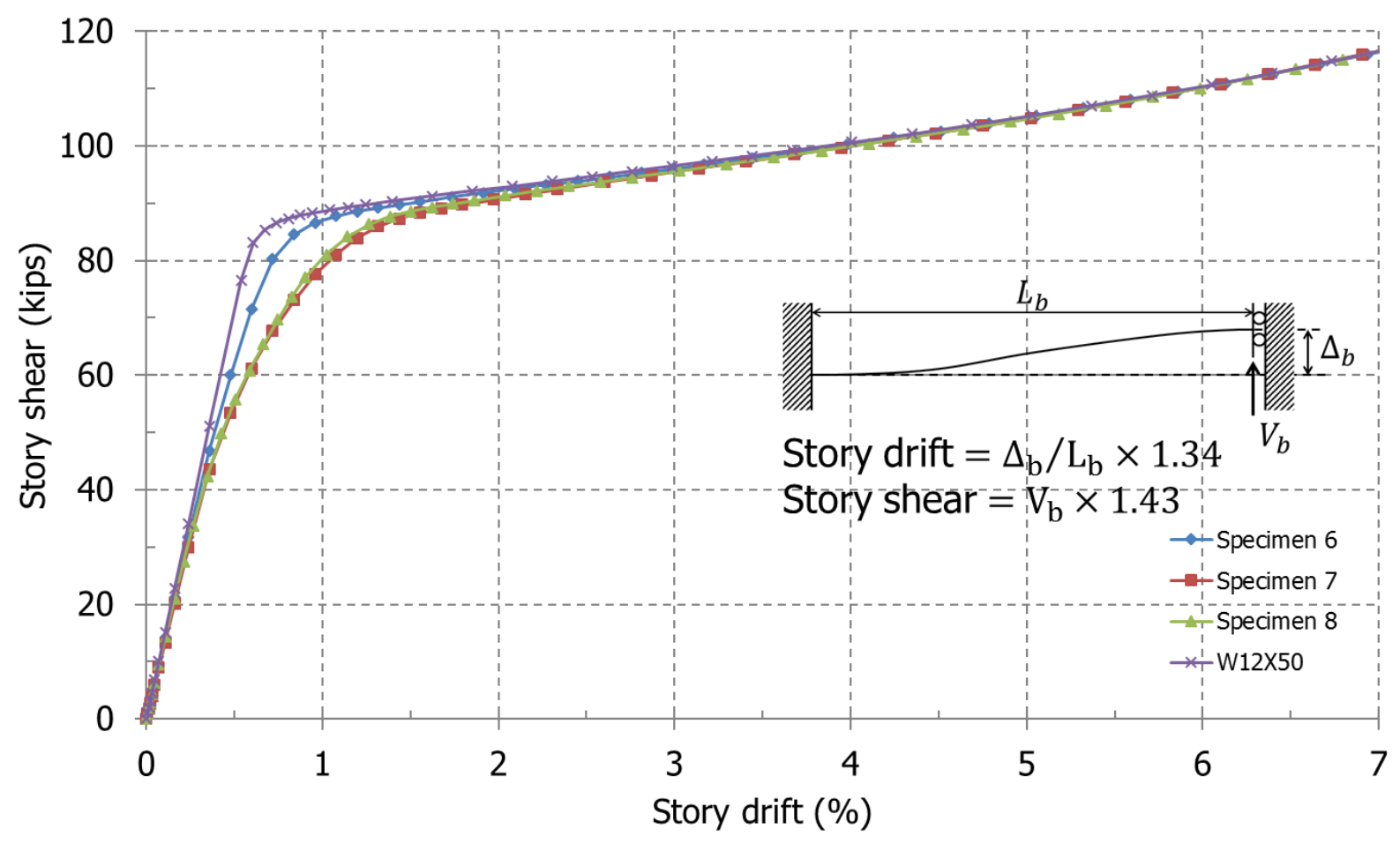

(a) Specimens made of $\mathrm{W} 12 \times 50$

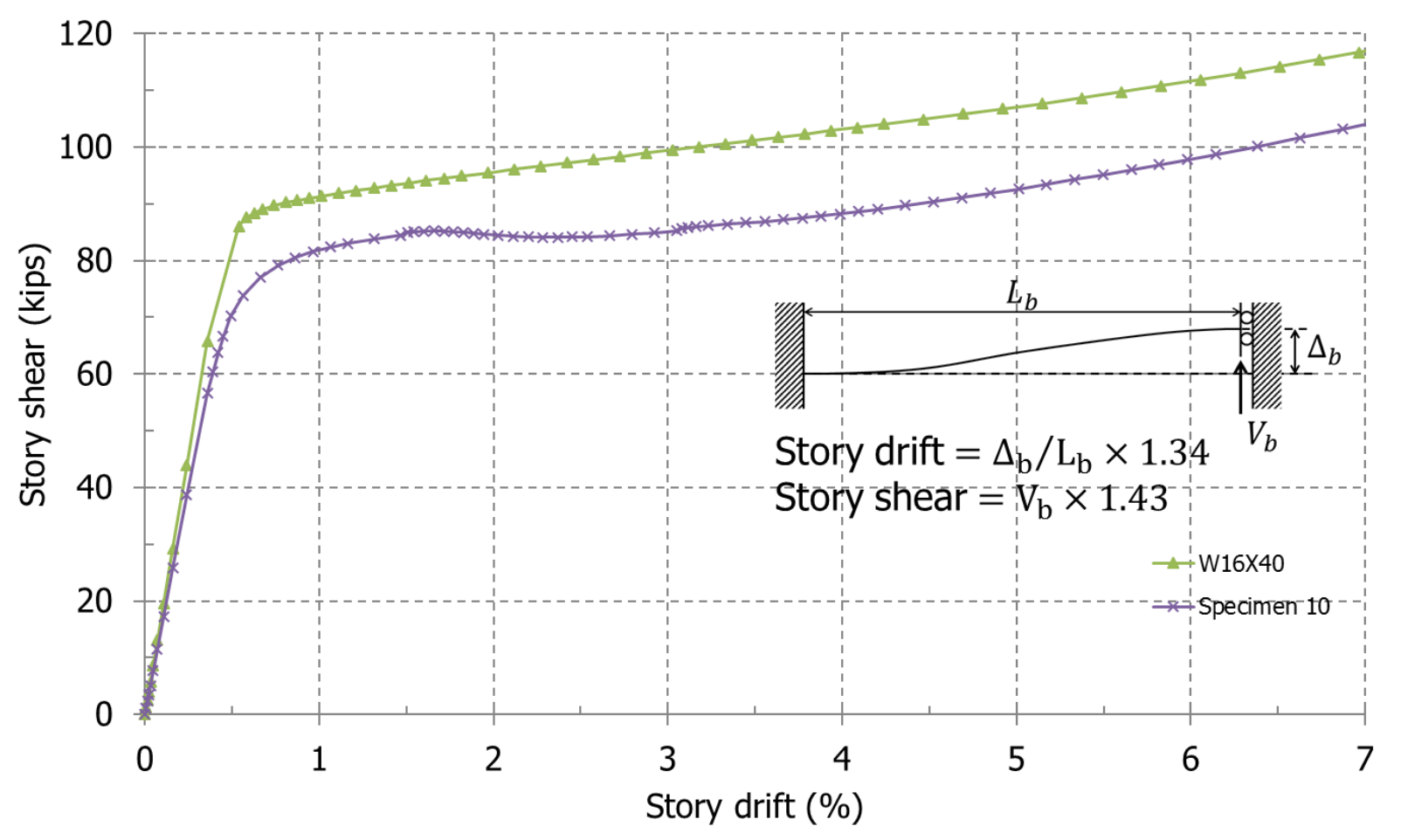

(b) Specimens made of W16x40 


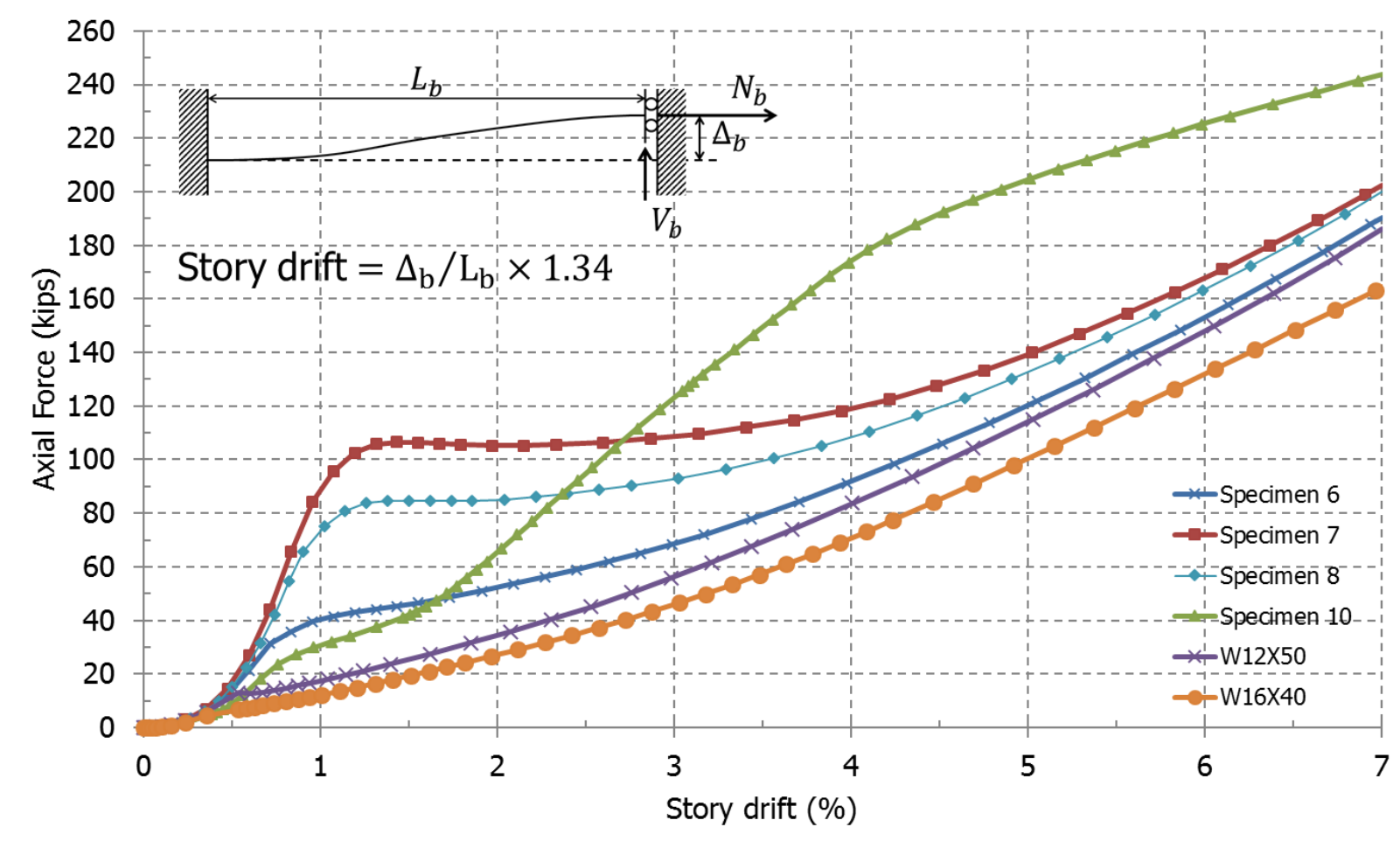

(c) Beam axial forces (tension)

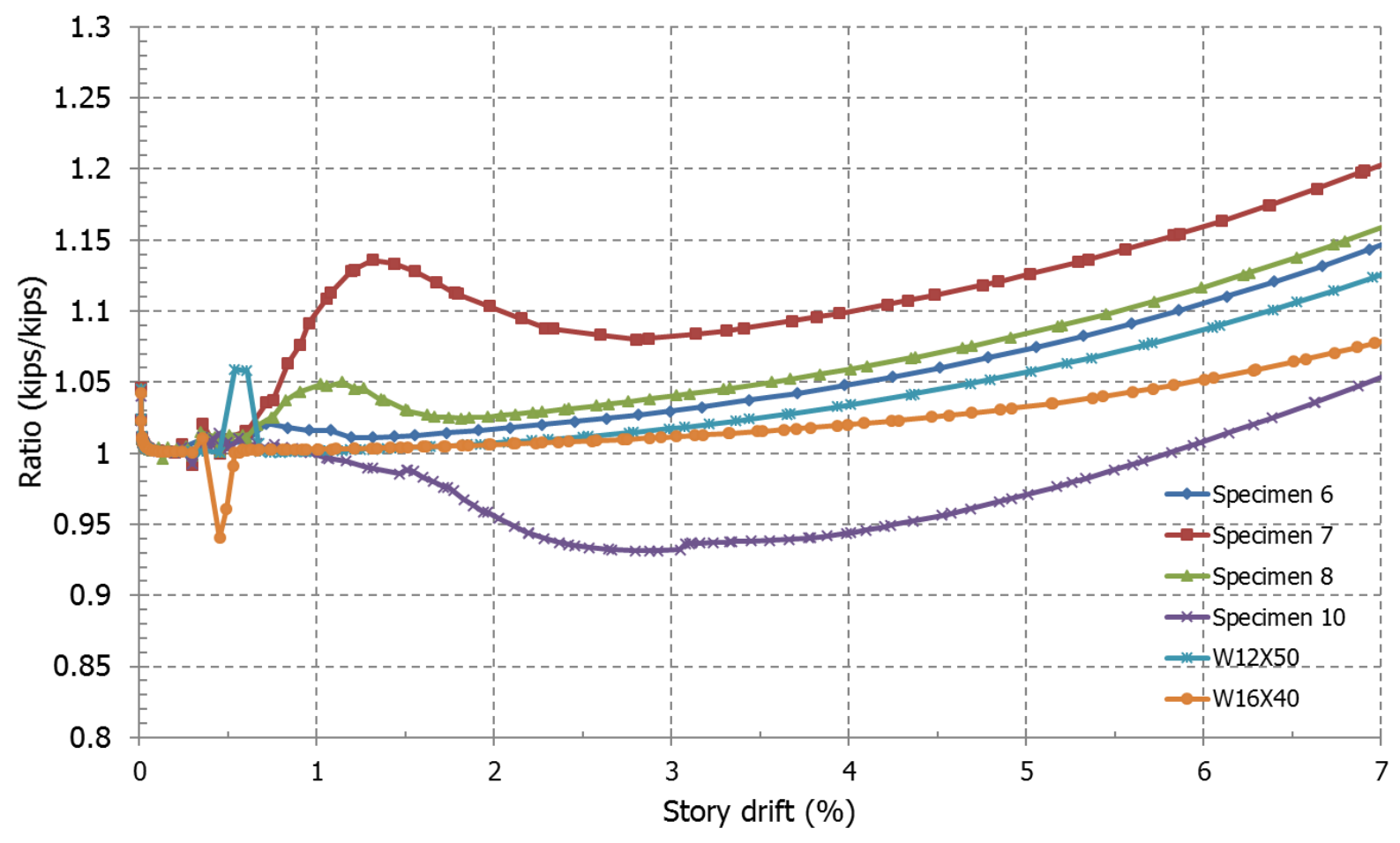

(d) Ratio of story shear force determined by finite element analysis considering geometric nonlinearity and ignoring geometric nonlinearity

Figure 12 - Nonlinear finite element analysis results with accounting for geometric nonlinearity for Phase 2 specimens $(1 \mathrm{kip}=4.45 \mathrm{kN})$ 
Specimen 6

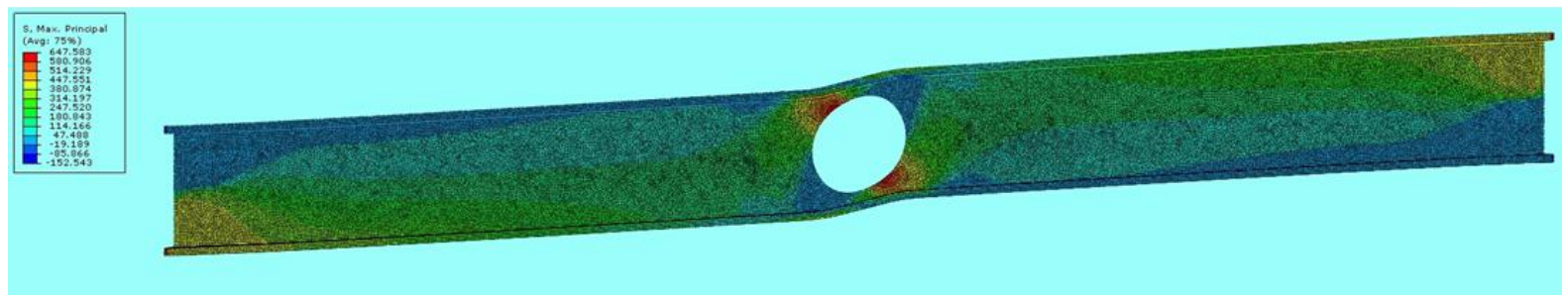

Specimen 7

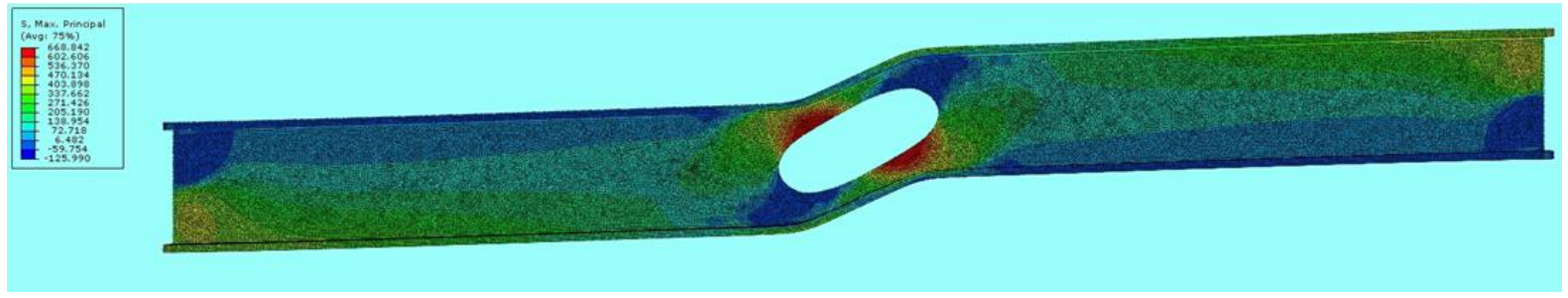

Specimen 8

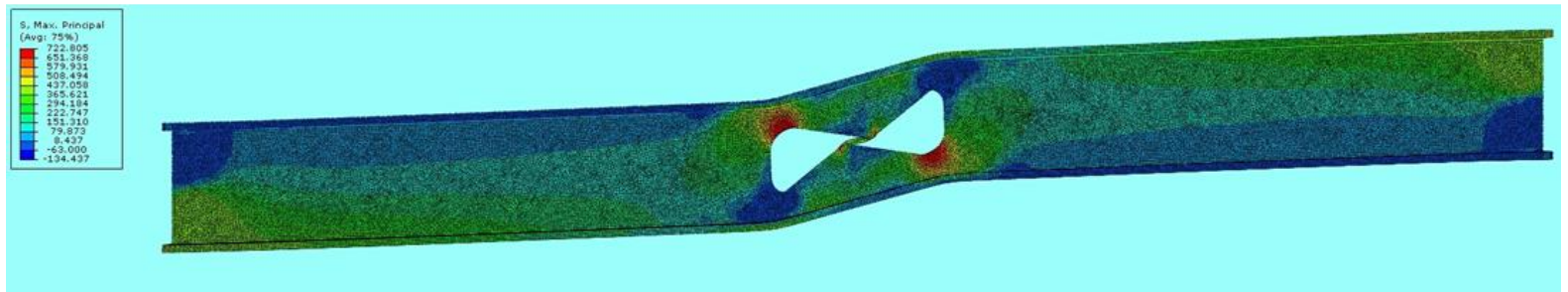

Specimen 10

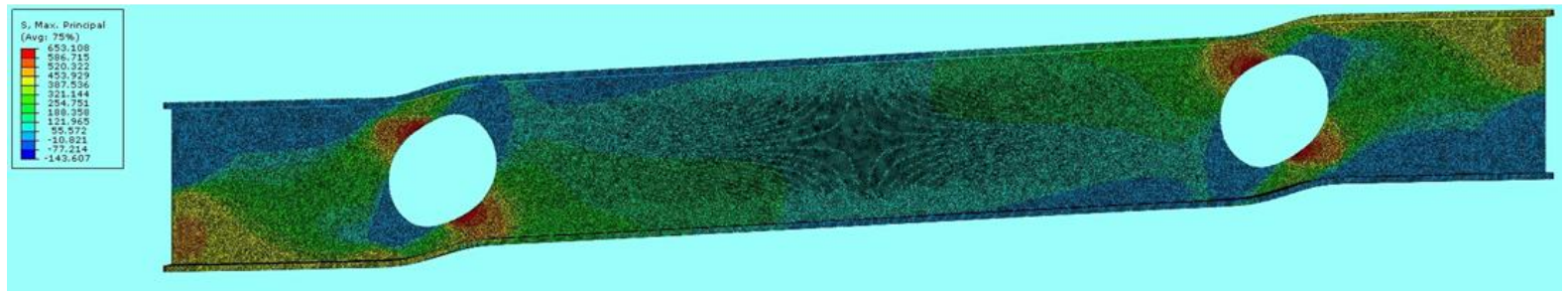

Figure 13 - Deformed shape (amplification factor $=1.5$ ) and maximum principal stress distribution at 5\% story drift, not including large displacement effects (units: MPa) 
Specimen 6

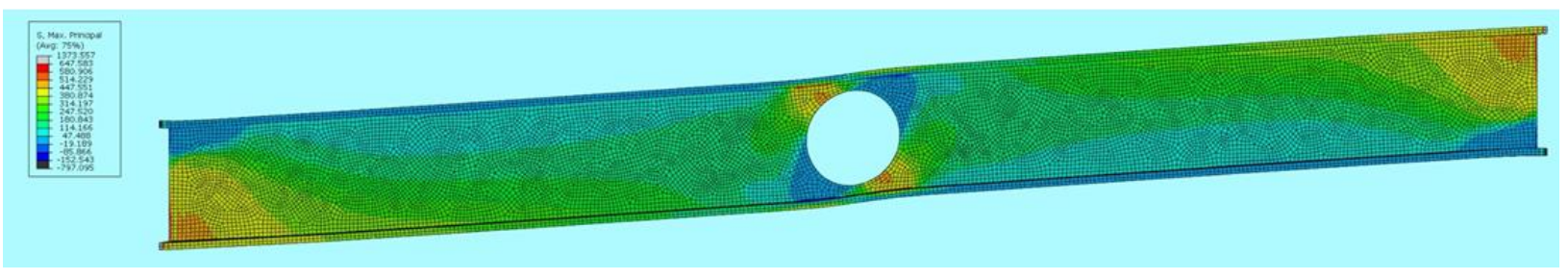

Specimen 7

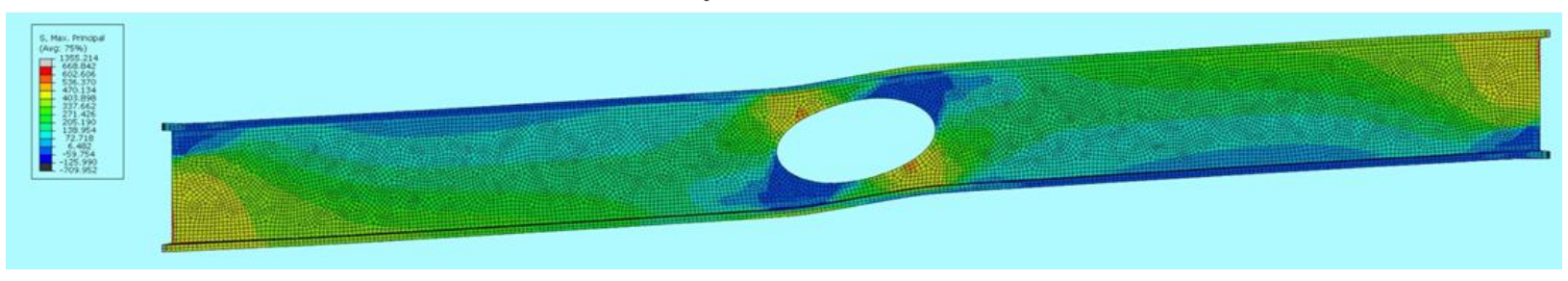

Specimen 8

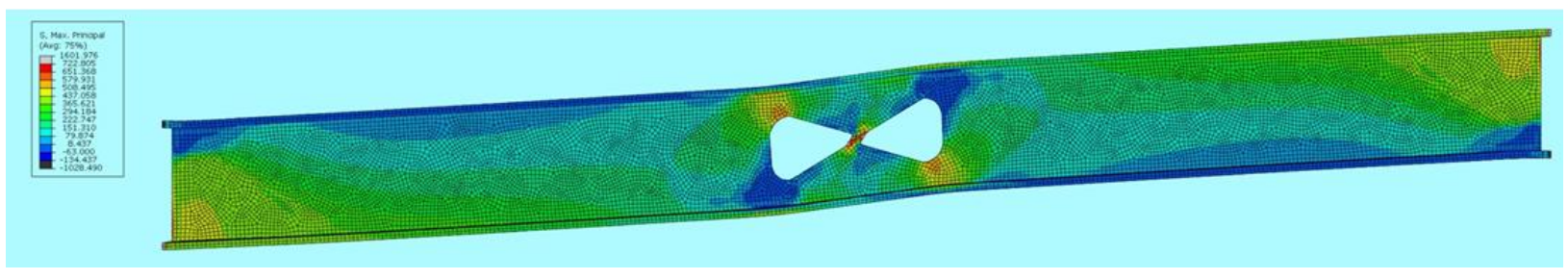

Specimen 10

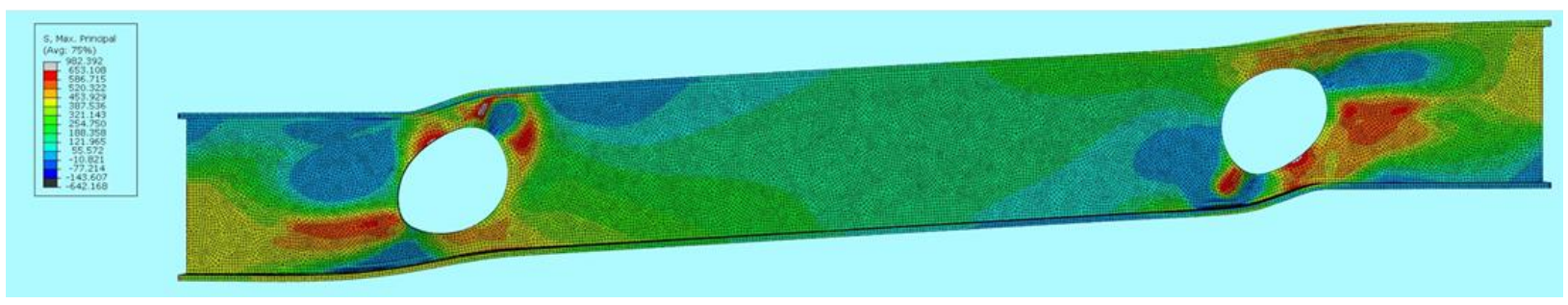

Figure 14 - Deformed shape (amplification factor $=1.5$ ) and maximum principal stress distribution at $5 \%$ story drift, including large displacement effects (units: MPa) 


\section{Specimen 6}

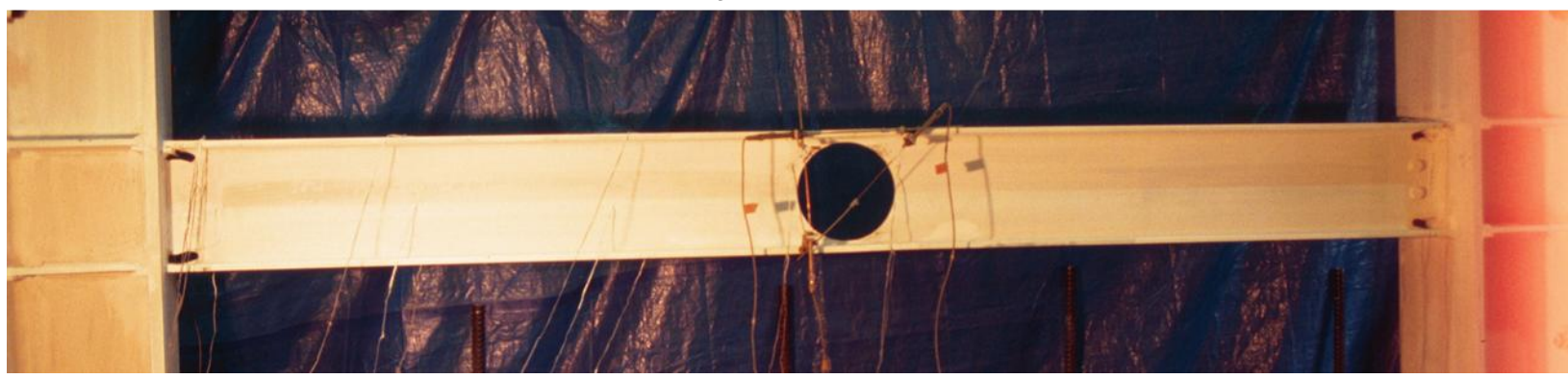

Specimen 7

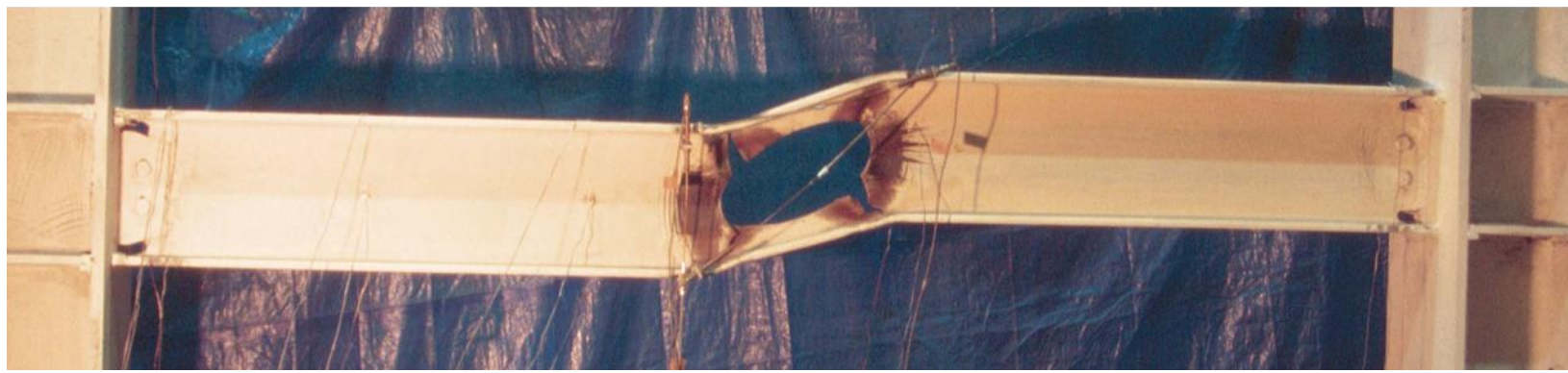

Specimen 8

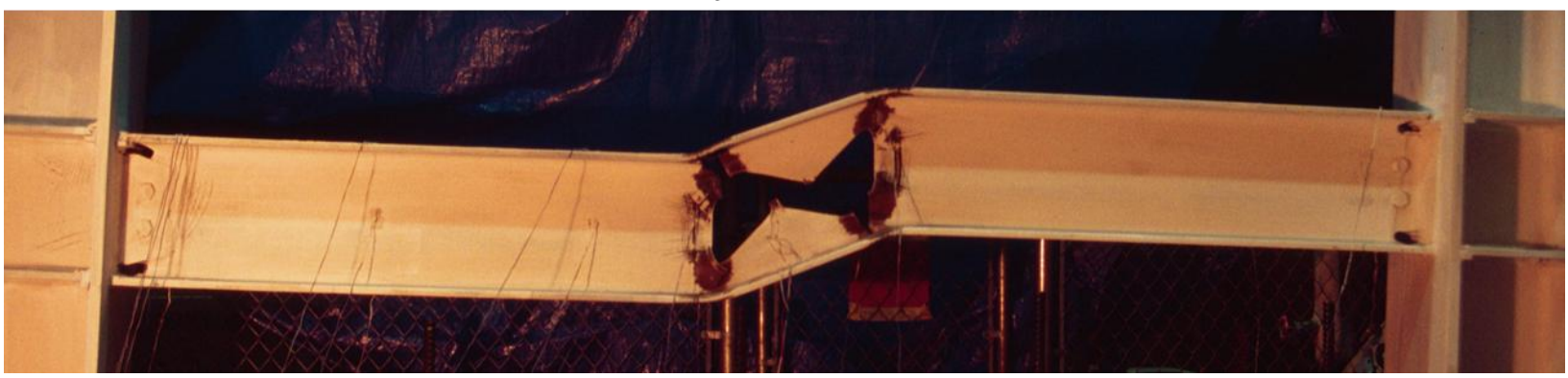

Specimen 9

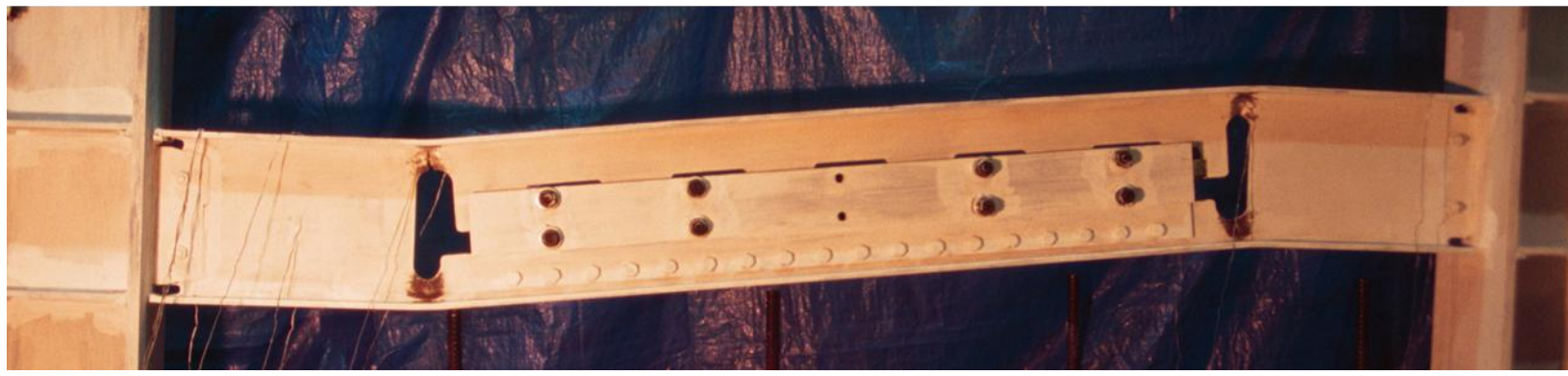

Specimen 10

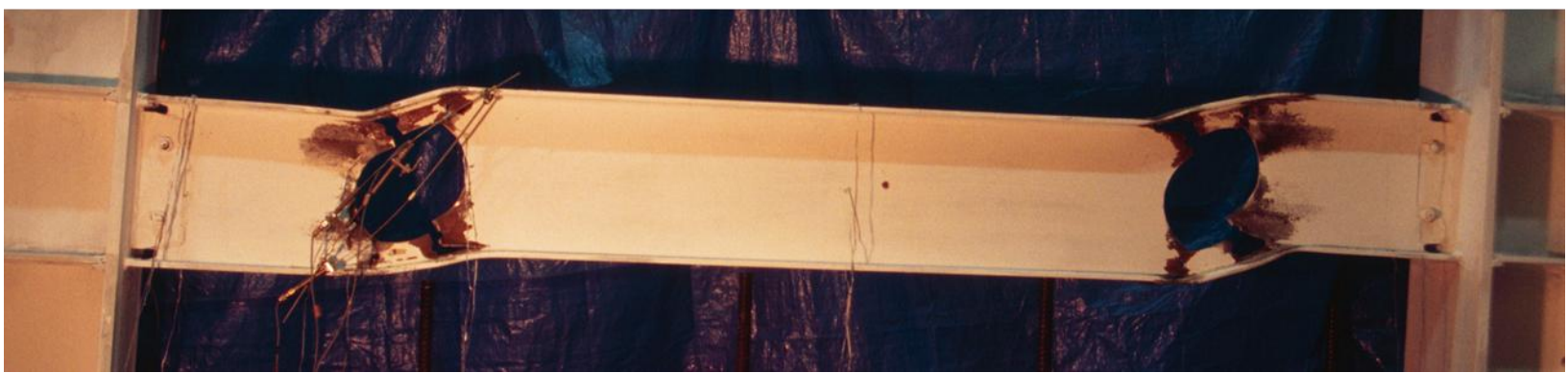

Figure 15 - Deformed shapes of Phase 2 specimens near the end of testing (Specimens 7, 8, 9, and 10) and early in the testing of Specimen 6. 

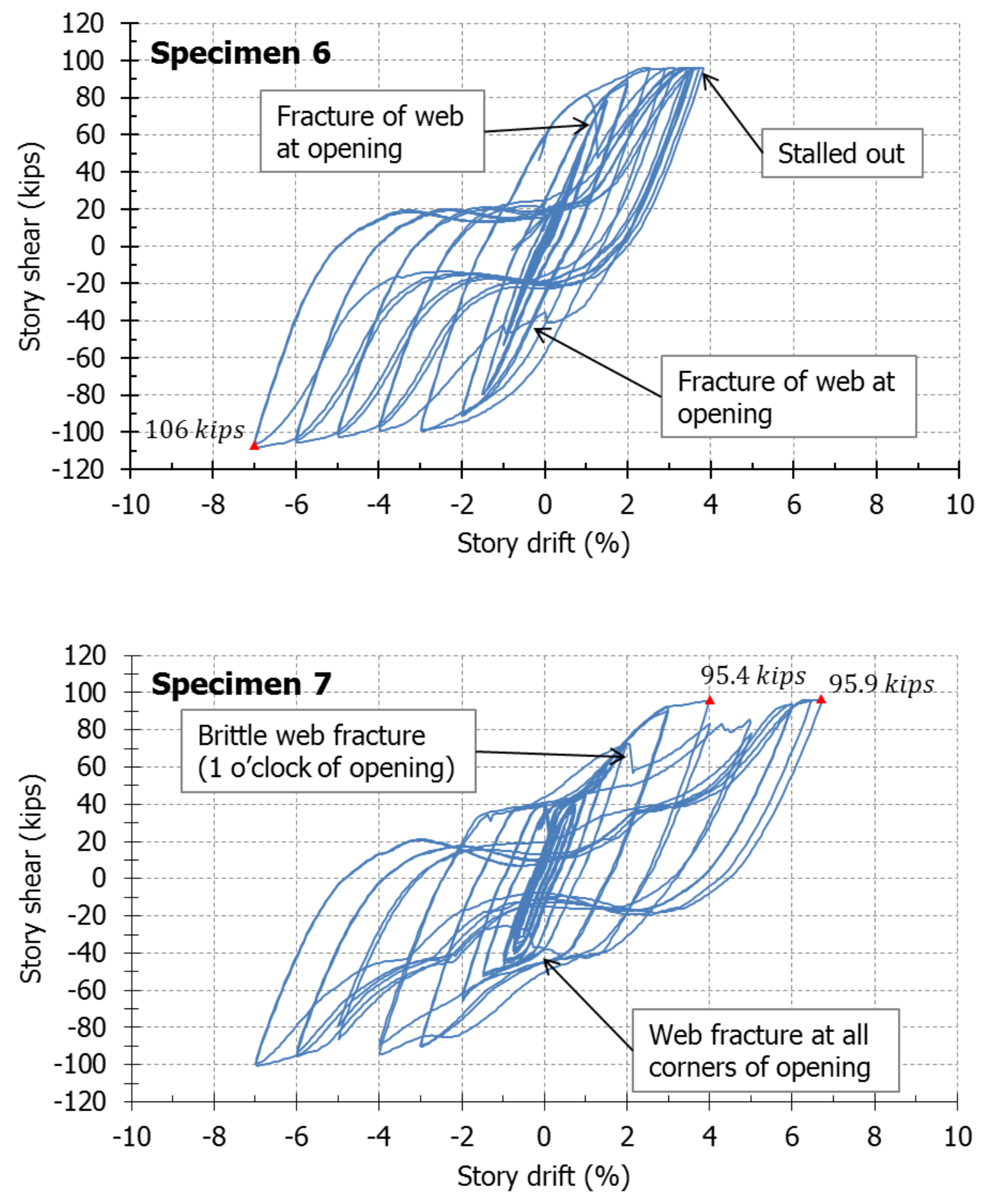

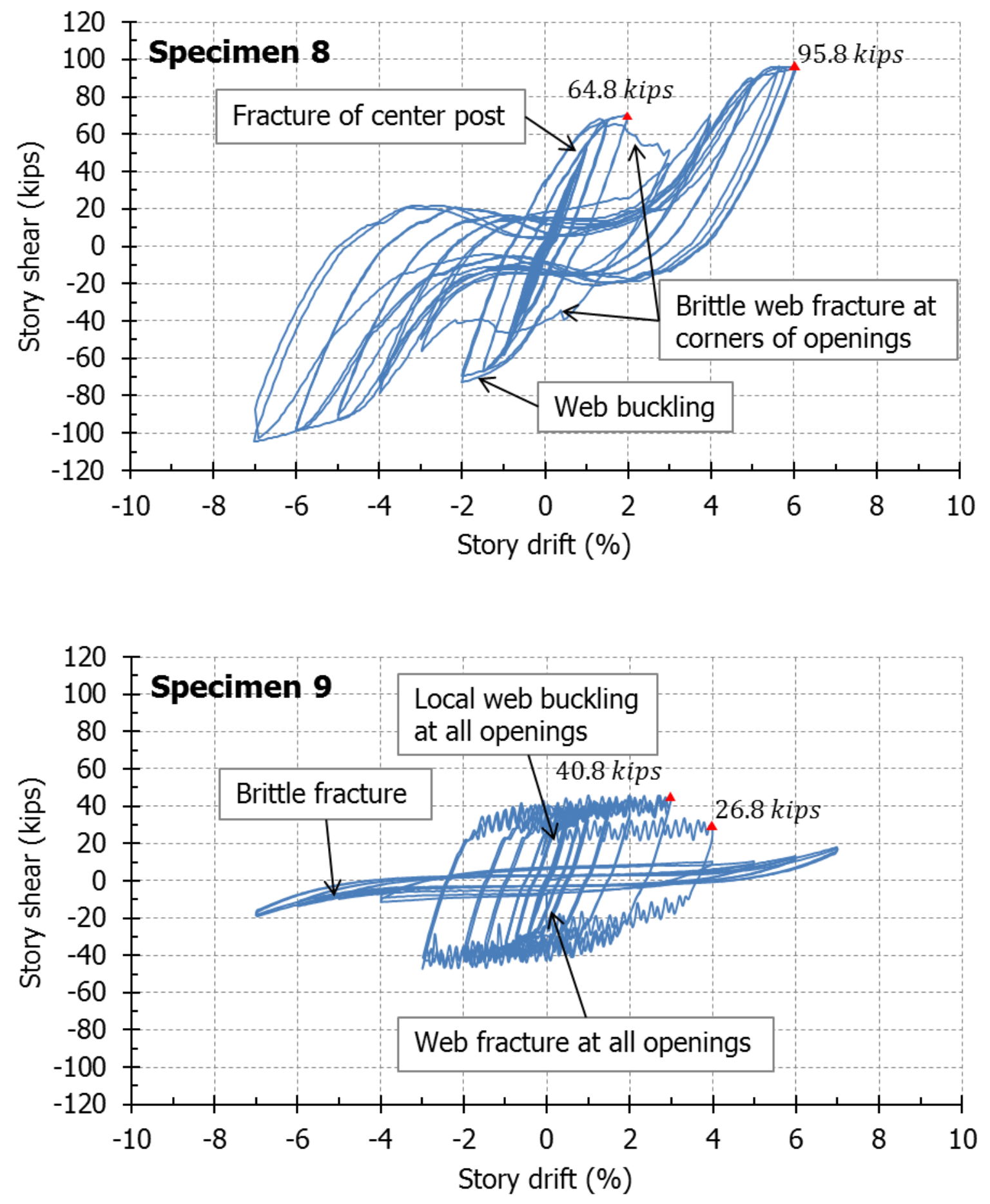

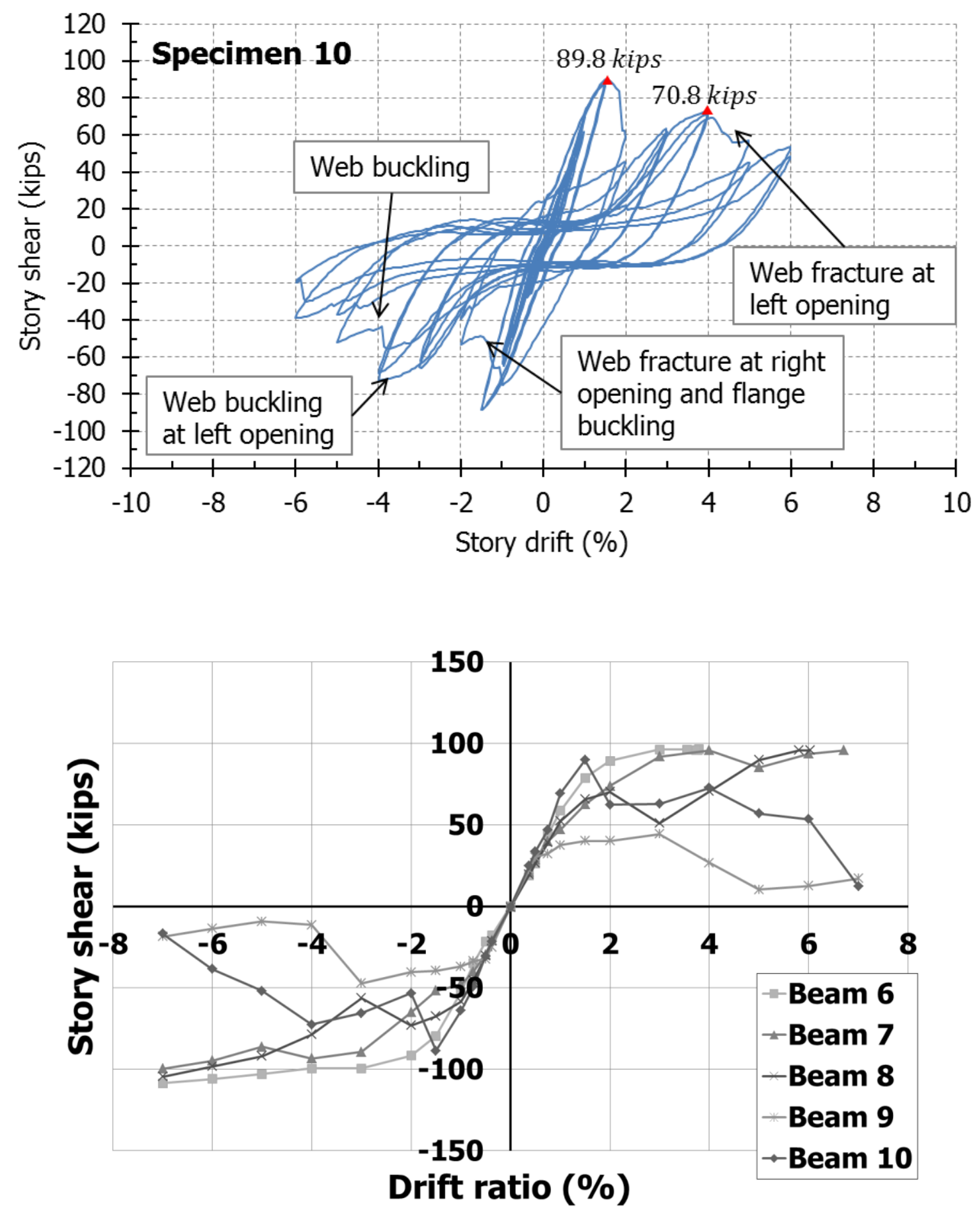

Figure $7-$ Story shear-story drift responses in Phase 2 specimens $(1 \mathrm{kip}=4.45 \mathrm{kN})$ 


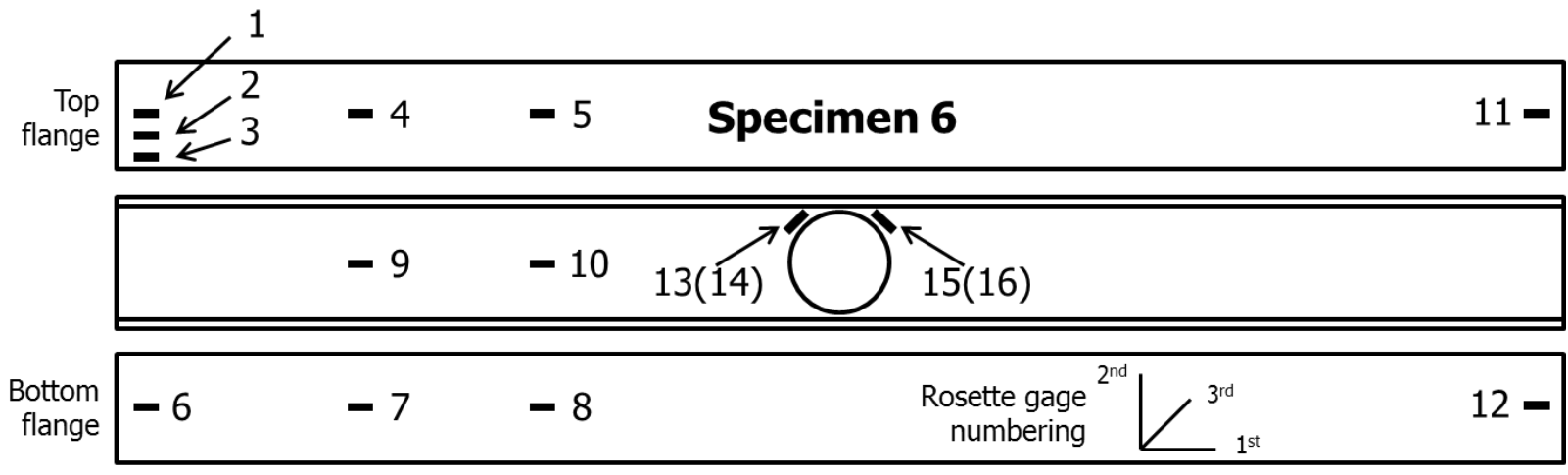

\section{Specimen 7}

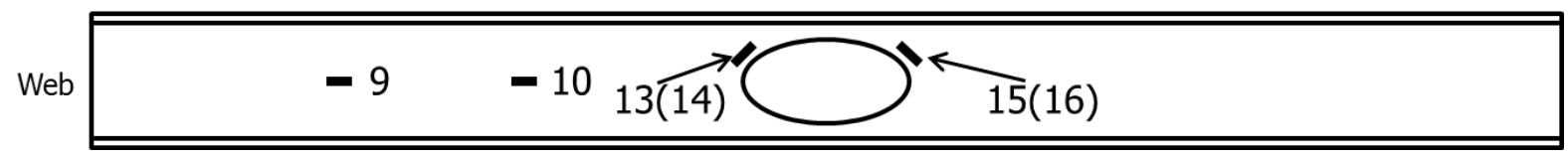

\section{Specimen 8}
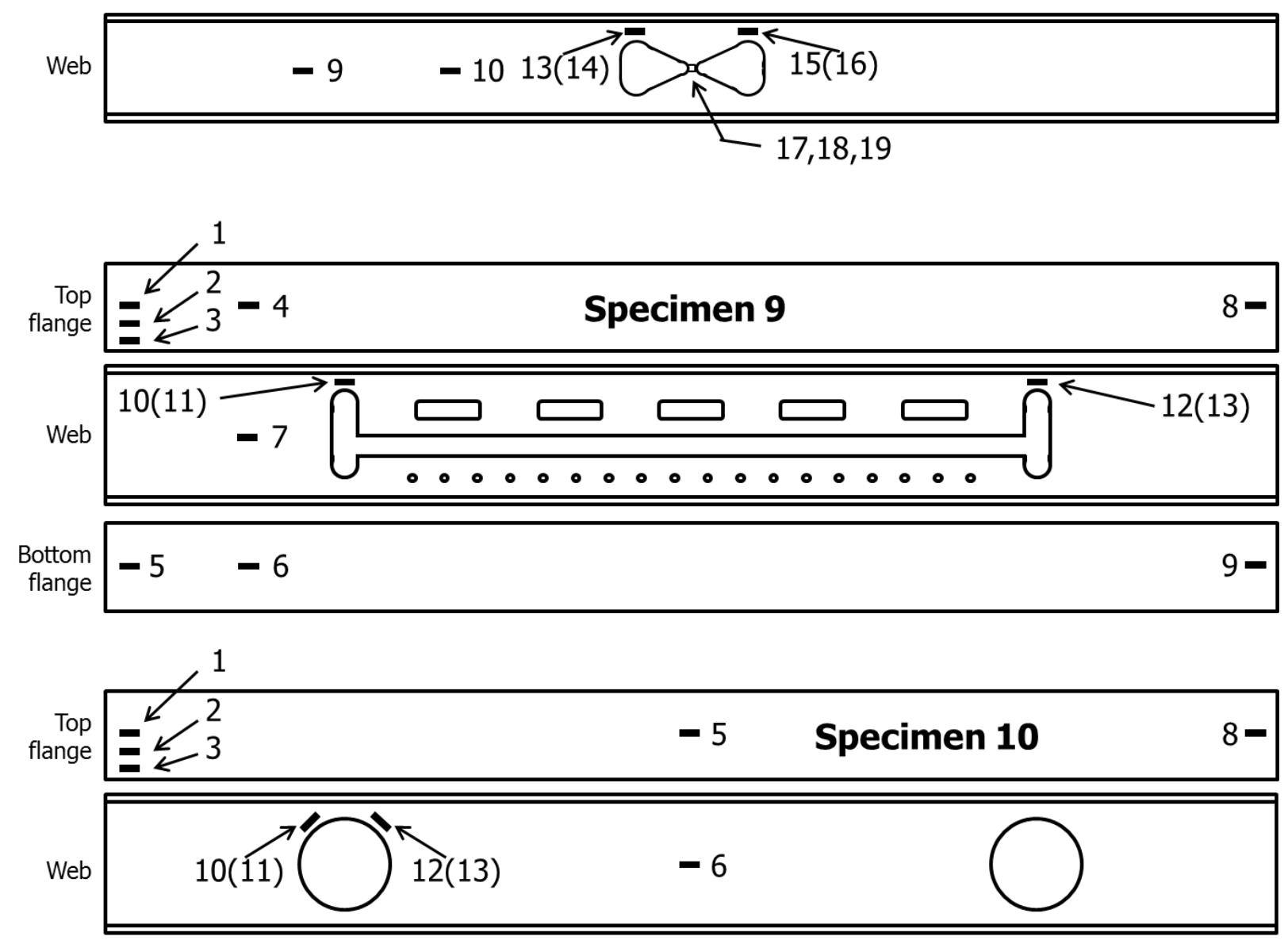

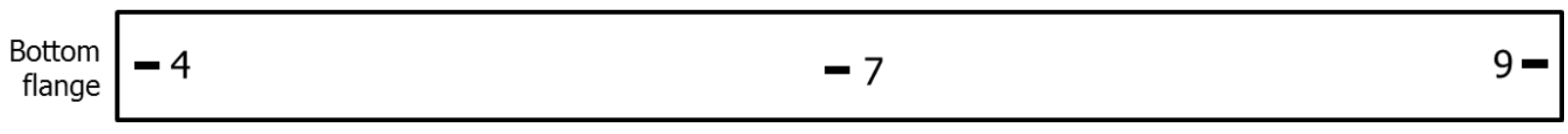


Figure 17 - The location of strain gages. (Strain gage number on the back side of the specimen shown in parentheses.)

Table 1 - Design details of Specimens 6 to 10

\begin{tabular}{|c|c|c|c|c|c|c|c|c||}
\hline $\begin{array}{c}\text { Spec- } \\
\text { imen }\end{array}$ & $\begin{array}{c}\text { Beam } \\
\text { shape }\end{array}$ & $\begin{array}{c}\text { Beam } \\
\text { depth, } \\
\text { in. (mm) }\end{array}$ & $\begin{array}{c}\text { Number } \\
\text { of web } \\
\text { opening(s) }\end{array}$ & $\begin{array}{c}\text { Size of } \\
\text { opening(s) } \\
\text { in. (mm) }\end{array}$ & $\begin{array}{c}\text { Opening } \\
\text { height / } \\
\text { beam } \\
\text { depth } \\
\text { to opening } \\
\text { center } \\
\text { from beam } \\
\text { end, in } \\
\text { (mm) }\end{array}$ & $\begin{array}{c}\text { Intended } \\
\text { inelastic } \\
\text { mechanism }\end{array}$ & $\begin{array}{c}\mathrm{V}_{\text {FEM }} \\
\text { (kips) }\end{array}$ \\
\hline 6 & W12x50 & $12.2(310)$ & 1 & $\begin{array}{c}10.1(256) \\
\text { in diameter }\end{array}$ & 0.826 & $\begin{array}{c}65.9 \\
(1673)\end{array}$ & Mode A & 87.8 \\
\hline 7 & W12x50 & $12.2(310)$ & 1 & $\begin{array}{c}15.5(394) \\
\text { in length } \\
7.75(197) \\
\text { in height }\end{array}$ & 0.635 & $\begin{array}{c}65.9 \\
(1673)\end{array}$ & Mode A & 88.3 \\
\hline 9 & W12x50 & $12.2(310)$ & 2 & $\begin{array}{c}16.7(425) \\
\text { in length } \\
6.18(157) \\
\text { in height }\end{array}$ & 0.506 & $\begin{array}{c}65.9 \\
(1673)\end{array}$ & Mode A & 88.6 \\
\hline 10 & W16x40 & $16.0(407)$ & 2 & $\begin{array}{c}10.5(267) \\
\text { in diameter }\end{array}$ & 0.656 & $25.9(657)$ & Mode A & 81.6 \\
\hline
\end{tabular}

Note: "n.a." stands for "not applicable".

Table 2 - Steel material properties based on tensile tests

\begin{tabular}{|c|c|c|c|c|c|}
\hline \multirow{2}{*}{ Specimen } & Location & $\begin{array}{c}\text { Upper yield } \\
\text { stress (ksi) }\end{array}$ & $\begin{array}{c}\text { Dynamic yield } \\
\text { stress at 0.2\% } \\
\text { offset (ksi) }\end{array}$ & $\begin{array}{c}\text { Strain at the } \\
\text { onset of strain } \\
\text { hardening (\%) }\end{array}$ & $\begin{array}{c}\text { Initial strain } \\
\text { hardening } \\
\text { modulus (ksi) }\end{array}$ \\
\hline \multirow{2}{*}{$6,7,8$} & Flange & 53.4 & 50.9 & 1.9 & 363 \\
\cline { 2 - 6 } & Web & 56.0 & 53.2 & 2.8 & 503 \\
\hline \multirow{2}{*}{9,10} & Flange & 58.4 & 56.6 & 1.3 & 720 \\
\cline { 2 - 6 } & Web & 61.7 & 61.7 & 1.8 & 571 \\
\hline
\end{tabular}

\begin{tabular}{||c|c|c|c|c||}
\hline Specimen & Location & $\begin{array}{c}\text { Modulus of } \\
\text { elasticity }(\mathrm{ksi})\end{array}$ & $\begin{array}{c}\text { Tensile strength } \\
(\mathrm{ksi})\end{array}$ & Elongation (\%) \\
\hline \multirow{2}{*}{$6,7,8$} & Flange & 28700 & 67.5 & 24.7 \\
\cline { 2 - 5 } & Web & 32600 & 68.4 & 28.1 \\
\hline 9,10 & Flange & 23200 & 78.7 & 20.3 \\
\hline
\end{tabular}




\begin{tabular}{|l|c|c|c|c|}
\hline & Web & 63200 & 80.1 & 17.6 \\
\hline
\end{tabular}

Note: $1 \mathrm{ksi}=6.895 \mathrm{MPa}$ 
Table 3 - Manufacturer's mill test data for steel

\begin{tabular}{|c|c|c|c||}
\hline Specimens & $\begin{array}{c}\text { Yield strength } \\
(\mathrm{ksi})\end{array}$ & $\begin{array}{c}\text { Tensile strength } \\
(\mathrm{ksi})\end{array}$ & $\begin{array}{c}\text { Elongation } \\
(\%)\end{array}$ \\
\hline $6,7,8$ & 54.0 & 74.5 & 21.5 \\
\hline 9,10 & 59.0 & 79.8 & 21.9 \\
\hline
\end{tabular}

Note: $1 \mathrm{ksi}=6.895 \mathrm{MPa}$

Table 4 - Story shear and drift results from the tests

\begin{tabular}{|c|c|c|c|c|c|c|c|c|}
\hline \multirow{2}{*}{ Spec. } & \multicolumn{2}{|c|}{$\begin{array}{c}\text { Maximum story } \\
\text { shear } V_{\max } \text { (kips) }\end{array}$} & \multicolumn{2}{|c|}{$\begin{array}{c}\text { Story drift at } V_{\max } \\
(\%)\end{array}$} & \multicolumn{2}{c|}{$\begin{array}{c}\text { Story shear at yield } \\
\text { point }{ }^{1)}(\mathrm{kips})\end{array}$} & \multicolumn{2}{c|}{$\begin{array}{c}\text { Story drift at yield } \\
\text { point (\%) }\end{array}$} \\
\cline { 2 - 9 } & $(+)$ & $(-)$ & $(+)$ & $(-)$ & $(+)$ & $(-)$ & $(+)$ & $(-)$ \\
\hline 6 & +96.1 & -108 & +3.10 & -6.99 & +85.1 & -87.7 & +1.80 & -1.83 \\
\hline 7 & +96.2 & -101 & +6.47 & -6.95 & +83.5 & -86.3 & +2.54 & -2.88 \\
\hline 8 & +96.2 & -104 & +5.64 & -7.01 & +63.4 & -63.0 & +1.40 & -1.24 \\
\hline 9 & +45.8 & -47.1 & +1.01 & -3.00 & +38.2 & -37.7 & +0.92 & -0.92 \\
\hline 10 & +89.9 & -88.6 & +1.56 & -1.47 & +81.8 & -84.0 & +1.28 & -1.40 \\
\hline
\end{tabular}

Note: 1 kip $=4.45 \mathrm{kN}$

1) Defined based on ATC 24 [18]

Table 5-Plastic analysis results based on the calculated mechanisms

\begin{tabular}{|c|c|c|c|c|c|c|c|}
\hline \multirow{2}{*}{\multicolumn{2}{|c|}{$\frac{\text { Plastified T-sections }}{\text { Location }^{1)}}$}} & \multicolumn{2}{|c|}{ Specimen 6} & \multicolumn{2}{|c|}{ Specimen 7} & \multicolumn{2}{|c|}{ Specimen 10} \\
\hline & & Left & Right & Left & Right & Left & Right \\
\hline \multirow{2}{*}{ Distance $^{2)}$ (in.) } & $\mathrm{SH}$ & 2.52 & 2.52 & 5.04 & 5.04 & 4.20 & 2.36 \\
\hline & $\mathrm{PP}$ & 3.05 & 3.03 & 5.04 & 5.04 & 4.20 & 2.89 \\
\hline \multirow{2}{*}{$y_{P N A}$ (in.) } & SH & 0.349 & 0.349 & 0.385 & 0.385 & 1.70 & 0.122 \\
\hline & $\mathrm{PP}$ & 0.352 & 0.352 & 0.377 & 0.377 & 1.39 & 0.124 \\
\hline \multirow{2}{*}{$M_{T p}$ (kips-in.) } & $\mathrm{SH}$ & 103 & 103 & 219 & 219 & 271 & 125 \\
\hline & $\mathrm{PP}$ & 74.6 & 74.6 & 125 & 125 & 257 & 54.9 \\
\hline \multirow{2}{*}{$C_{T}^{3)}(\mathrm{kips})$} & $\mathrm{SH}$ & \multicolumn{2}{|c|}{0} & \multicolumn{2}{|c|}{0} & 154 & -154 \\
\hline & PP & \multicolumn{2}{|c|}{0} & \multicolumn{2}{|c|}{0} & 151 & -151 \\
\hline \multirow{2}{*}{$V_{b p}^{4)}$ (kips) } & $\mathrm{SH}$ & \multicolumn{2}{|c|}{81.9} & \multicolumn{2}{|c|}{86.8} & 39.5 & 59.5 \\
\hline & $\mathrm{PP}$ & \multicolumn{2}{|c|}{49.3} & \multicolumn{2}{|c|}{49.4} & 56.8 & 1.2 \\
\hline \multirow{2}{*}{$V_{c p}^{5)}$ (kips) } & $\mathrm{SH}$ & \multicolumn{2}{|c|}{117} & \multicolumn{2}{|c|}{124} & \multicolumn{2}{|c|}{85.0} \\
\hline & $\mathrm{PP}$ & \multicolumn{2}{|c|}{70.4} & \multicolumn{2}{|c|}{70.7} & \multicolumn{2}{|c|}{81.2} \\
\hline$V_{c p, \text { avg }}{ }^{6)}$ (kips) & & \multicolumn{2}{|c|}{93.7} & \multicolumn{2}{|c|}{97.4} & \multicolumn{2}{|c|}{83.1} \\
\hline
\end{tabular}




\begin{tabular}{|c|c|c|c|c||}
\hline$V_{\text {exp }} / V_{c p, \text { avg }}$ & 1.09 & 1.01 & 1.07 \\
\hline$V_{F E M} / V_{c p, \text { avg }}$ & 0.94 & 0.91 & 0.98 \\
\hline
\end{tabular}

Note: $1 \mathrm{kip}=4.45 \mathrm{kN}, 1$ in. $=25.4 \mathrm{~mm}$; $\mathrm{SH}$ refers to strain hardening; PP refers to perfectly plastic.

1) Plastic hinge location, offset to the left or right from the center of opening

2) Horizontal distance (absolute) from the center of opening to the plastic hinge

3) Axial force in the T-section associated with beam moment at the center of opening; (+) means compression, (-) means tension

4) Beam shear associated with first-order mechanism involving T-section plastic moments, $M_{T p}$

5) $V_{c p}$ is the story shear associated with first-order mechanism beam shear $V_{b p}$.

6) $V_{c p \text {, avg }}$ is the average of the two values determined using strain-hardening ( $\mathrm{SH}$ ) equation and its simplification for perfectly-plastic (PP) conditions.

7) $V_{\text {exp, avg }}$ is taken as the average of the two values determined experimentally for the (+) and (-) directions in Table 4.

8) $V_{F E M}$ is determined from the monotonic FEM analyses as reported in Table 1.

Table 6 - Story drift (\%) at the yielding of each portion of the specimen

\begin{tabular}{|c|c|c|c|c|c|c|}
\hline \multicolumn{2}{|c|}{ Location } & Spec. 6 & Spec. 7 & Spec. 8 & \multirow{2}{*}{$\begin{array}{c}\text { Spec. } 9 \\
\# 10,11, \\
12,13\end{array}$} & \multirow{2}{*}{$\begin{array}{c}\text { Spec. } 10 \\
\# 10,11 \\
12,13\end{array}$} \\
\hline \multirow{2}{*}{$\begin{array}{c}\text { Webs around } \\
\text { openings }\end{array}$} & Gage No. & \multicolumn{3}{|c|}{$\# 13,14,15,16$} & & \\
\hline & Drift & $1 \%$ & $0.5 \sim 0.75 \%$ & $1 \%$ & $1 \%$ & $0.75 \sim 1 \%$ \\
\hline \multirow{2}{*}{ Web post } & Gage No. & - & - & $\#[17,18,19]$ & - & - \\
\hline & Drift & - & - & $0.25 \%$ & - & - \\
\hline \multirow{2}{*}{$\begin{array}{l}\text { Flanges at } \\
\text { connections }\end{array}$} & Gage No. & \multicolumn{3}{|c|}{$\# 1,2,3,6,11,12$} & $\begin{array}{c}\# 1,2,3,5, \\
8,9\end{array}$ & $\begin{array}{c}\# 1,2,3,4, \\
8,9\end{array}$ \\
\hline & Drift & $1.5 \%$ & $2 \%$ & $2 \%$ & n.y. & $1.5 \%$ \\
\hline \multirow{2}{*}{$\begin{array}{c}\text { Flanges } \\
\text { away } \\
\text { connections }\end{array}$} & Gage No. & \multicolumn{3}{|c|}{$\# 4,5,7,8$} & $\# 4,6$ & $\# 5,7$ \\
\hline & Drift & n.y. & n.y. & n.y. & n.y. & n.y. \\
\hline \multirow{2}{*}{ Web centers } & Gage No. & \multicolumn{3}{|c|}{$\# 9,10$} & $\# 7$ & \#6 \\
\hline & Drift & n.y. & n.y. & n.y. & n.y. & n.y. \\
\hline
\end{tabular}

Note: "n.y." stands for "no yielding". 